Revue des patrimoines

22 | 2013

La peinture murale : héritage et renouveau

\title{
La prospection des peintures murales des Pays de la Loire
}

Christian Davy

\section{OpenEdition}

Journals

Édition électronique

URL : http://journals.openedition.org/insitu/10792

DOI : 10.4000/insitu.10792

ISSN : 1630-7305

Éditeur

Ministère de la culture

Référence électronique

Christian Davy, «La prospection des peintures murales des Pays de la Loire », In Situ [En ligne],

22 | 2013, mis en ligne le 15 novembre 2013, consulté le 19 avril 2019. URL : http://

journals.openedition.org/insitu/10792; DOI : 10.4000/insitu.10792

Ce document a été généré automatiquement le 19 avril 2019.

\section{(c) $($ i) $(9)$}

In Situ Revues des patrimoines est mis à disposition selon les termes de la licence Creative Commons Attribution - Pas d'Utilisation Commerciale - Pas de Modification 4.0 International. 


\title{
La prospection des peintures murales des Pays de la Loire
}

\author{
Christian Davy
}

Communication présentée lors des journées d'études consacrées à l'Actualité de la recherche en peinture murale, organisées par le musée des Monuments français les 25 et 26 octobre 2011, à la Cité de l'architecture et du patrimoine.

\section{Présentation de l'opération}

1 Le mouvement de reconnaissance de l'art de la fresque et de la peinture murale en France au XIX ${ }^{\mathrm{e}}$ siècle a établi un palmarès des régions qui est resté figé par la suite ${ }^{1}$. Ainsi, le Poitou, la Bourgogne ou le Berry ont été considérés comme riches en peintures murales, au contraire des Pays de la Loire où pourtant des œuvres de premier plan avaient également été repérées. Les nombreuses découvertes réalisées à partir de la décennie 1960 et le renouvellement de la recherche permettent d'affirmer aujourd'hui que les Pays de la Loire constituent un territoire particulièrement riche dans le domaine de la peinture murale.

2 La Région des Pays de la Loire a donc identifié cette forme d'expression comme un sujet patrimonial prioritaire. Le Service du patrimoine de la Région des Pays de la Loire a conçu une action de prospection, de recherche et de valorisation, en même temps qu'un dispositif de soutien spécifique pour les propriétaires de peintures murales.

Une prospection des peintures murales a été engagée en 2010 de manière à évaluer l'impact potentiel de ce patrimoine aux points de vue culturel, scientifique, pédagogique, économique et touristique. À partir des résultats de cette opération menée sur l'ensemble $\mathrm{du}$ territoire régional seront déterminées les études scientifiques spécifiques à entreprendre. La recherche et la valorisation pourront dès lors être menées de concert afin que le public puisse s'approprier ce patrimoine le plus rapidement possible. Les potentialités élargies du multimédia apparaissent particulièrement bien adaptées pour la 
peinture murale, permettant de placer, en certaines circonstances, le public dans un rôle d'acteur ou de collaborateur de la recherche scientifique. Ces différentes opérations pourront être menées en partenariat avec les collectivités territoriales ou les institutions sensibilisées aux enjeux de la peinture murale.

\section{Les deux temps de l'opération thématique « à la découverte des peintures murales des Pays de la Loire »}

4 L'objectif de la prospection était d'évaluer l'ensemble, ou corpus, constitué par les peintures murales réalisées depuis le Moyen Âge jusqu'à nos jours conservées dans le territoire des Pays de la Loire. Pour cela, il était indispensable d'entrer dans chacun des édifices susceptibles d'en posséder. La durée de l'opération a été établie en tenant compte du nombre de communes dans chacun des départements, du temps nécessaire aux prises de contact, aux déplacements et à la visite des édifices, ainsi qu'à la saisie des données recueillies. La prospection a débuté en avril 2010 et s'est achevée en janvier 2011. Quatre départements ont été prospectés simultanément. Sous le pilotage scientifique de Christian Davy, chercheur au pôle Inventaire-Recherche, et suite à un appel à prestation, Érik Zeimert, architecte, a eu la charge de la Loire-Atlantique ; Christine Leduc-Gueye, historienne de l'art indépendante, celle du Maine-et-Loire et de la Mayenne, et avec Pierrick Barreau, historien, celle de la Vendée. Le territoire de la Sarthe, qui avait fait l'objet d'un inventaire partiel de ses peintures murales quelques années auparavant ${ }^{2}$, a été abordé différemment : Raphäle Nourrisson, stagiaire, a mené la prospection à partir de la documentation existante.

Le champ d'investigation a été limité aux édifices de propriété publique et à ceux de propriété privée dans lesquels la présence de peintures murales était déjà connue par les professionnels du patrimoine. À cette liste, se sont ajoutés d'autres édifices, signalés localement lors du passage du prospecteur. L'enregistrement des données recueillies s'est effectué sur le principe d'une fiche par édifice, quel que soit le nombre de peintures murales conservées dans celui-ci. Une interface (fig. $\mathbf{n}^{\circ} \mathbf{1}$ ) a été spécifiquement créée par Yann Le Duff, service du patrimoine, sur le tableur Excel pour faciliter la saisie et l'interrogation. Dans un objectif de rapidité, le niveau de l'information demandée a été placé à un degré simple, garantissant l'homogénéité et donc le traitement des données, chaque fiche comporte des informations sur la localisation, les caractères physiques (emplacement, visibilité, état...), l'iconographie et la datation de la peinture observée. Six photographies au maximum illustrent chacune des fiches. L'analyse des résultats de la prospection clôt donc cette première étape et la synthèse ouvre les perspectives de recherche et de valorisation de la peinture murale des Pays de la Loire dont la réalisation constituera la seconde étape. 


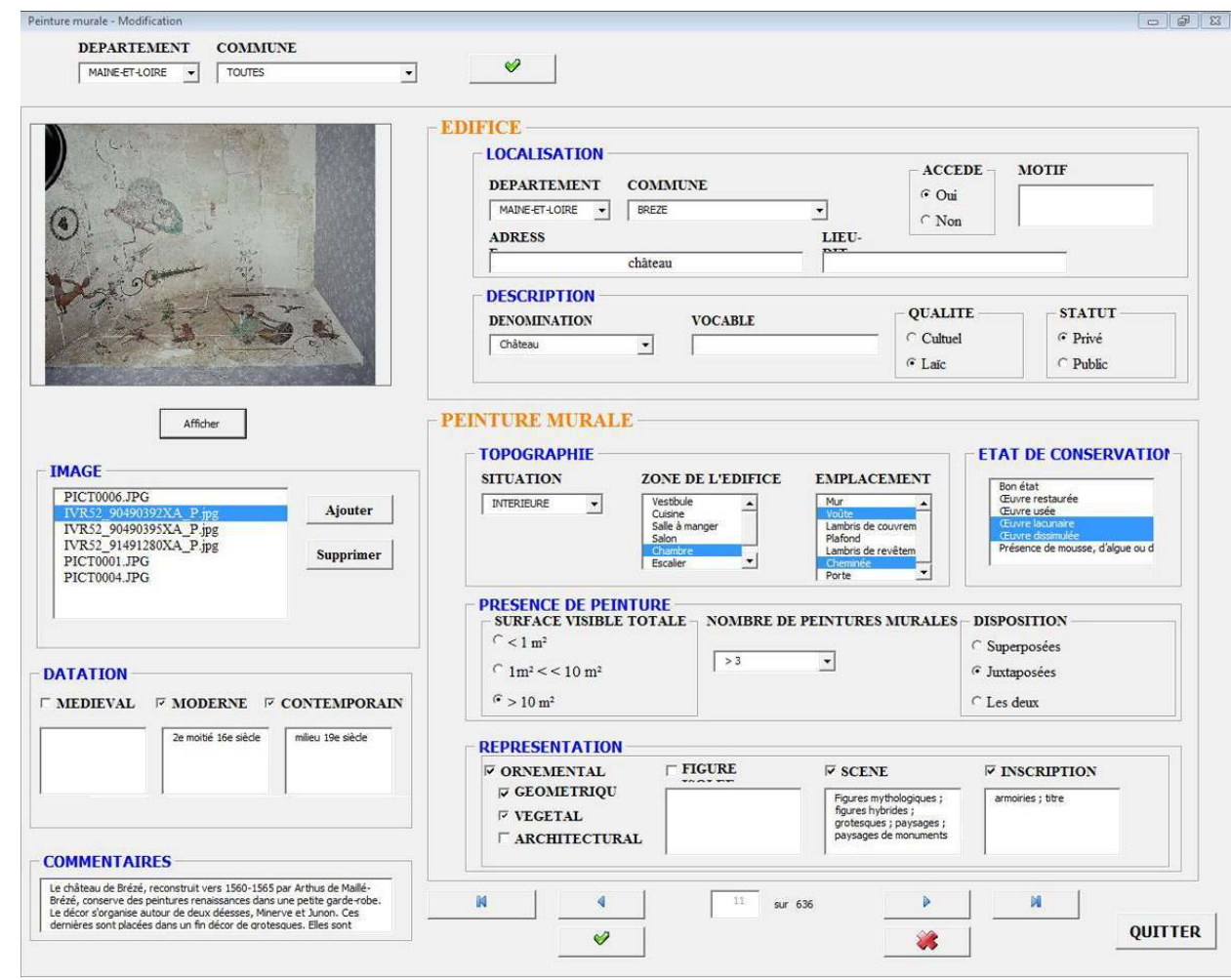

Interface de saisie pour le logiciel Excel.

Conception Le Duff, Yann. (c) Conseil régional des Pays de la Loire, service du patrimoine, 2010.

\section{Quelle peinture murale retenir?}

6 Définir la peinture murale est délicat, du fait de la variété des éléments qui la constituent (support, couche picturale, etc.) et de l'ambivalence de certains termes qui la décrivent. A priori limitée au mur, la peinture murale peut se trouver en réalité sur tout élément de l'architecture : voûte, plafond, lambris de couvrement, cheminée, mais aussi sur les parois d'une grotte, comme il y a 25000 ans à Saulges en Mayenne - où elle est alors nommée peinture pariétale.

7 Le « support » de la peinture murale évoque aussi bien la maçonnerie qui porte l'enduit peint que cet enduit qui reçoit la couleur. L'enduit peint est souvent constitué de plusieurs couches, tandis que le niveau coloré des pigments définit la « couche picturale ». La peinture murale se pratique sur un support opaque : toute sorte de pierres, maçonnées ou non, chaux, plâtre, ciment, torchis ou pisé, bois, voire métal. Elle est exécutée aussi bien dans les espaces intérieurs que sur les façades extérieures.

Les techniques en peinture murale sont diverses, variant en fonction de la présence de liants ou non, de la qualité chimique de ceux-ci et de la nature des pigments utilisés. Dans la fresque, les pigments délayés dans l'eau sont fixés par le processus chimique de la carbonatation qui redonne une nature calcaire (carbonate de calcium ou CaCO3) à l'enduit peint. Toute fresque est ainsi une peinture murale, mais la réciprocité n'est pas vraie. Une peinture murale peut ainsi être réalisée à fresque, à la peinture à la chaux, à l'huile, à la cire, au silicate de potasse ou à l'acrylique. 
Le rapport à la monumentalité est un autre de ses caractères. La peinture murale participe de l'architecture en adoptant les proportions de l'édifice. Elle le finit en constituant l'« épiderme de l'architecture ", expression régulièrement entendue. Elle installe l'homme dans un espace monumental et dans un même temps dans un rapport au temps et à l'espace par la durée et le déplacement nécessaires à la lecture des multiples images qu'elle affiche (fig. $\mathbf{n}^{\circ} \mathbf{2}$ ).

Figure 2

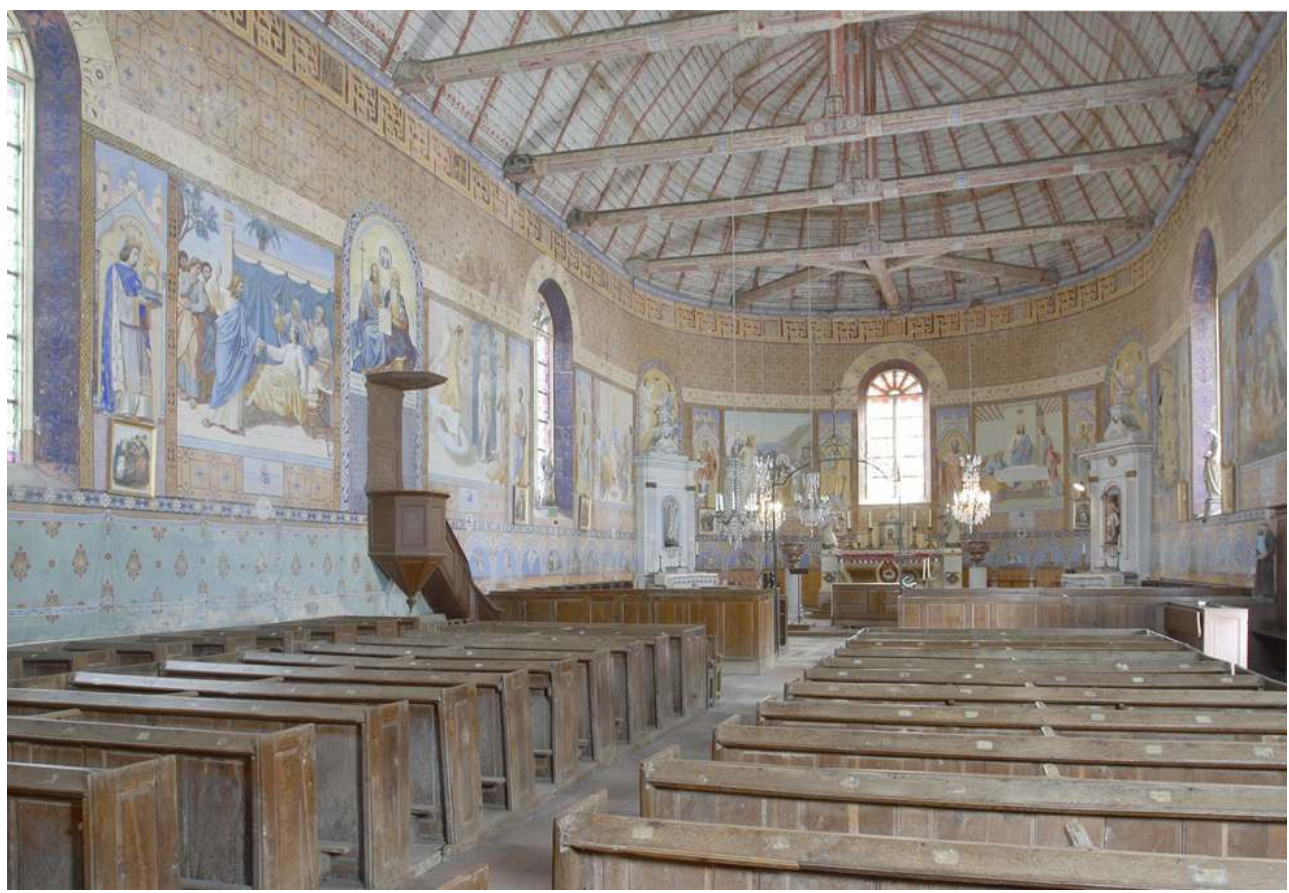

Conflans-sur-Anille (Sarthe), église paroissiale Saint-Maurice. Vue d'ensemble vers le nord-est.

Phot. Giraud, Patrice. (C) Conseil régional des Pays de la Loire, service du patrimoine, 2003. IVR52_20037200078NUCA

10 D'autres caractères permettent d'identifier aisément la peinture murale. Elle remplit plusieurs fonctions. Le jeu des couleurs et des formes décore un plan, colore un espace ou un volume architectural. Cependant la peinture murale est avant tout un support de communication. À chaque époque, l'individu ou le groupe a transmis ses idées par ce média. Au Moyen Âge, l'Église communiquait ses dogmes et ses préceptes moraux par la peinture murale à l'ensemble de ses fidèles. À l'époque moderne, elle est moins pratiquée, mais elle a continué d'être ainsi utilisée par des groupes restreints. Les décors peints des demeures nobles ou bourgeoises s'adressaient à l'entourage des commanditaires. Dès le XIX siècle, elle a retrouvé une large audience. Les peintures réalisées de nos jours sur les murs extérieurs s'adressent au public le plus vaste.

11 La capacité de toucher l'homme de manière diverse et simultanée est l'une de ses propriétés. La peinture murale transmet le plus souvent ses messages au moyen d'images organisées en programme iconographique : souvent l'image raconte une histoire et le programme énonce des idées. La peinture murale place le visiteur à la fois dans le registre de l'émotion et dans celui de la méditation. 


\section{Les principaux résultats de la prospection}

\section{Un vaste ensemble de peintures murales : de la peinture murale partout !}

2575 fiches ont été remplies par les prospecteurs pour autant d'édifices qui présentent de la peinture murale. Quatre communes sur cinq (1 203 sur 1 502) possèdent au moins un édifice à peinture murale. Leur répartition dans les cinq départements ${ }^{3}$ est homogène. La moyenne s'établit à 1,71 fiche par commune au niveau régional et varie peu d'un département à l'autre (fig. $\mathbf{n}^{\circ}$ ). Mais ce résultat, supérieur à l'estimation de départ, est d'ores et déjà inférieur à la réalité du terrain. Outre quelques peintures murales ayant échappé aux investigations à cause des contraintes de la prospection, des découvertes ont été effectuées depuis la clôture de l'opération. Ainsi, en mars 2011, un plafond peint entre 1630 et 1650 a été mis au jour lors d'un chantier de rénovation à Laval (Mayenne). En avril 2011, l'enquête d'inventaire menée dans la vallée du Loir en a repéré plusieurs dont une peinture murale du XVII ${ }^{\mathrm{e}}$ siècle dans une chapelle du XII ${ }^{\mathrm{e}}$ siècle. En septembre 2011, un mur peint au milieu du $\mathrm{XX}^{\mathrm{e}}$ siècle est découvert lors de la réhabilitation de l'ancien asile psychiatrique du Mans. Enfin, la création contemporaine produit continuellement.

Figure 3

\section{Répartition des édifices à peinture murale par commune}

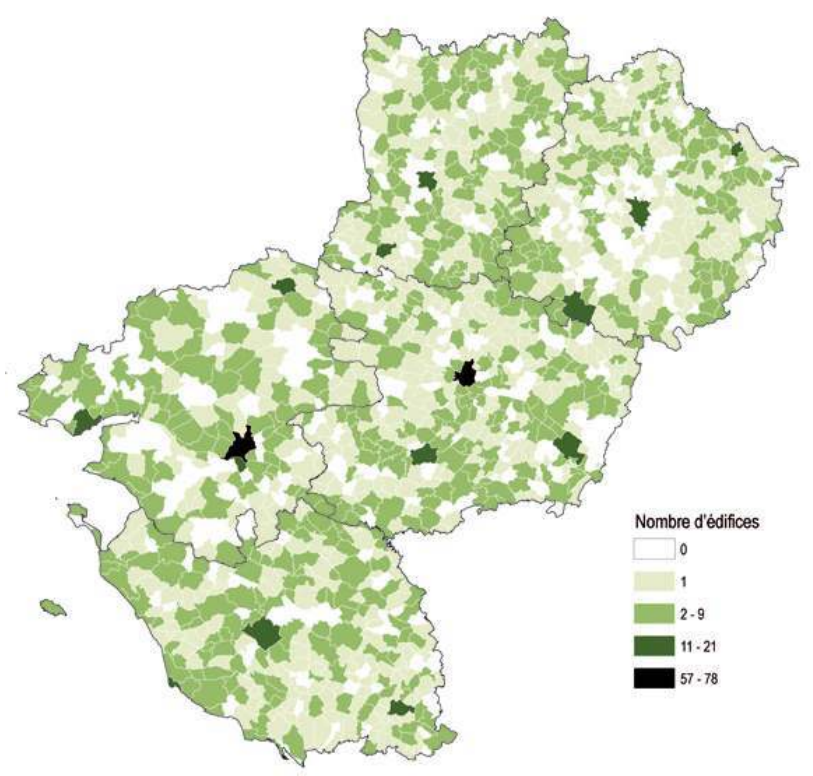

Répartition des édifices à peinture murale par commune.

Cartogr. Le Duff, Yann, Desvigne, Virginie. (c) Conseil régional des Pays de la Loire, service du patrimoine, 2011.

Le nombre de peintures murales conservées dans une commune semble directement lié à l'importance de la population. Les communes rurales conservent de 0 à 9 peintures 
murales et les villes moyennes de 11 à 21, à de rares exceptions près. Nantes et Angers en possèdent respectivement 57 et 78 .

\section{La quantité de peintures murales : 3600 décors de peinture murale}

L'un des caractères spécifiques de la peinture murale est la superposition de décors successifs. Chacun d'eux constitue alors une campagne picturale. Le nombre des décors superposés est en corrélation avec l'ancienneté de l'édifice. En effet, les édifices construits à l'époque contemporaine qui présentent de la peinture murale ne conservent le plus souvent qu'une seule campagne décorative. Ils représentent les trois quarts du corpus établi lors de la prospection. De ce fait les édifices qui conservent plusieurs peintures murales constituent un groupe restreint. Cependant, cela ne concerne pas moins de 662 édifices (fig. $\left.\mathbf{n}^{\circ} \mathbf{4}\right)$. Certains d'entre eux, comme l'église paroissiale SaintHilaire d'Asnières-sur-Vègre (Sarthe), conservent jusqu'à 17 peintures murales réalisées à des moments différents. Ils sont majoritairement des édifices anciens, construits à l'époque médiévale ou moderne. Les prospecteurs ont ainsi repéré 2575 édifices qui présentent un nombre de décors supérieur à 3600 .

Figure 4

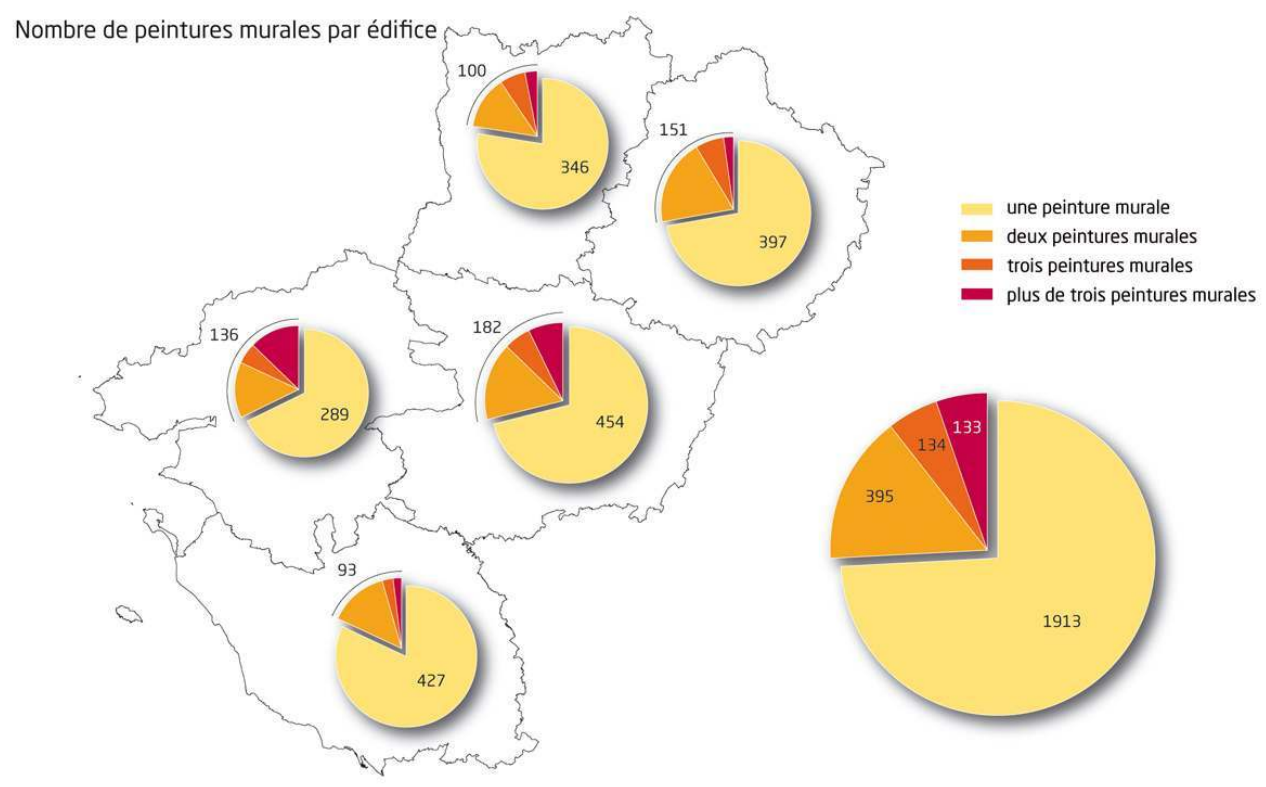

Répartition du nombre de peintures murales par édifice.

Cartogr. Le Duff, Yann, Desvigne, Virginie. @ Conseil régional des Pays de la Loire, service du patrimoine, 2011.

La répartition géographique des édifices à plusieurs peintures murales s'avère hétérogène. L'estuaire de la Loire et la région nantaise en Loire-Atlantique, la partie méridionale de la Vendée, le Maine-et-Loire et le nord de la Sarthe abritent la majorité de ces édifices. La dernière zone citée est le résultat de l'étude thématique menée sur le territoire. 


\section{Intérieur, extérieur? La situation des peintures murales}

16 La peinture murale se trouve à l'intérieur des édifices et comme toutes les idées reçues, celle-ci n'est pas entièrement exacte. Si près des trois quarts des peintures murales ont bien été exécutés dans un bâtiment, près d'un quart l'a été à l'extérieur. Ainsi, les parois extérieures des murs de 636 édifices ont été ornées de peinture murale. Cette pratique a existé à toutes les époques, mais le phénomène s'est développé à l'époque contemporaine et plus précisément dans la seconde moitié du XXe et au début du XXI ${ }^{e}$ siècle. Il apparaît de manière plus accentuée dans les deux départements littoraux, Loire-Atlantique et Vendée, qui rassemblent près des deux tiers des cas.

17 Par ailleurs, 69 édifices conservent des peintures murales qui ornent à la fois leurs volumes intérieurs et leurs parois extérieures. Il s'agit le plus souvent d'églises dont les tympans extérieurs sont également peints ; de châteaux qui présentent, outre une décoration intérieure, des enduits extérieurs peints ou incisés ; d'édifices industriels dont les murs tant intérieurs qu'extérieurs ont servi de support à l'imagination des grafeurs.

\section{Le perpétuel renouvellement des peintures murales}

18 La fresque, l'une des techniques de la peinture murale, permet en théorie d'obtenir des décors d'une durée quasi-infinie, grâce au processus de la carbonatation. Cependant la peinture murale ne dure en général que le temps de la pertinence du message qu'elle transmet ou le temps d'une mode décorative. Ensuite, elle est souvent recouverte par un nouveau décor plus au goût du jour. Cette accumulation, généralement associée à des dégradations dues à des conditions de conservation médiocres sous nos climats, constitue l'une des caractéristiques les plus étonnantes de l'art de la peinture murale. Le renouvellement par superposition, courant au Moyen Âge et à l'époque moderne, semble disparaître à l'époque contemporaine sur l'ensemble du territoire régional. En effet, une forte majorité des édifices de cette époque conserve une seule peinture murale. Toutefois le phénomène de recouvrement par une autre décoration peinte connaît depuis quelques décennies une nouvelle phase de développement avec le remplacement régulier et rapide des grafs (fig. $n^{\circ} 5, n^{\circ} 6, n^{\circ} 7$ ). 
Figure 5

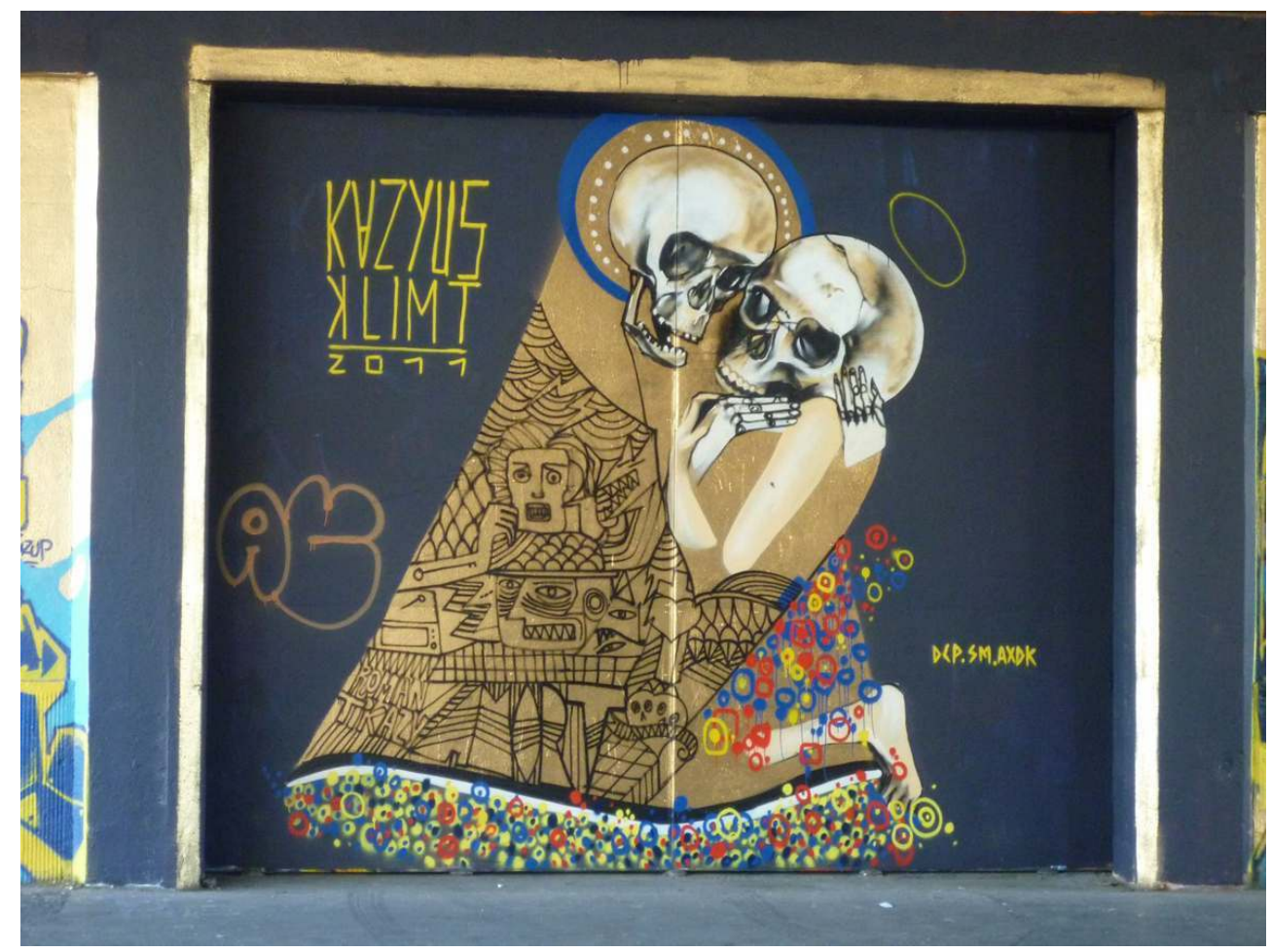

Nantes, Pont Lu. Graf en avril 2011.

PHOT. DAVY, CHRISTIAN. (C) CHRISTIAN DAVY, 2011.

Figure 6

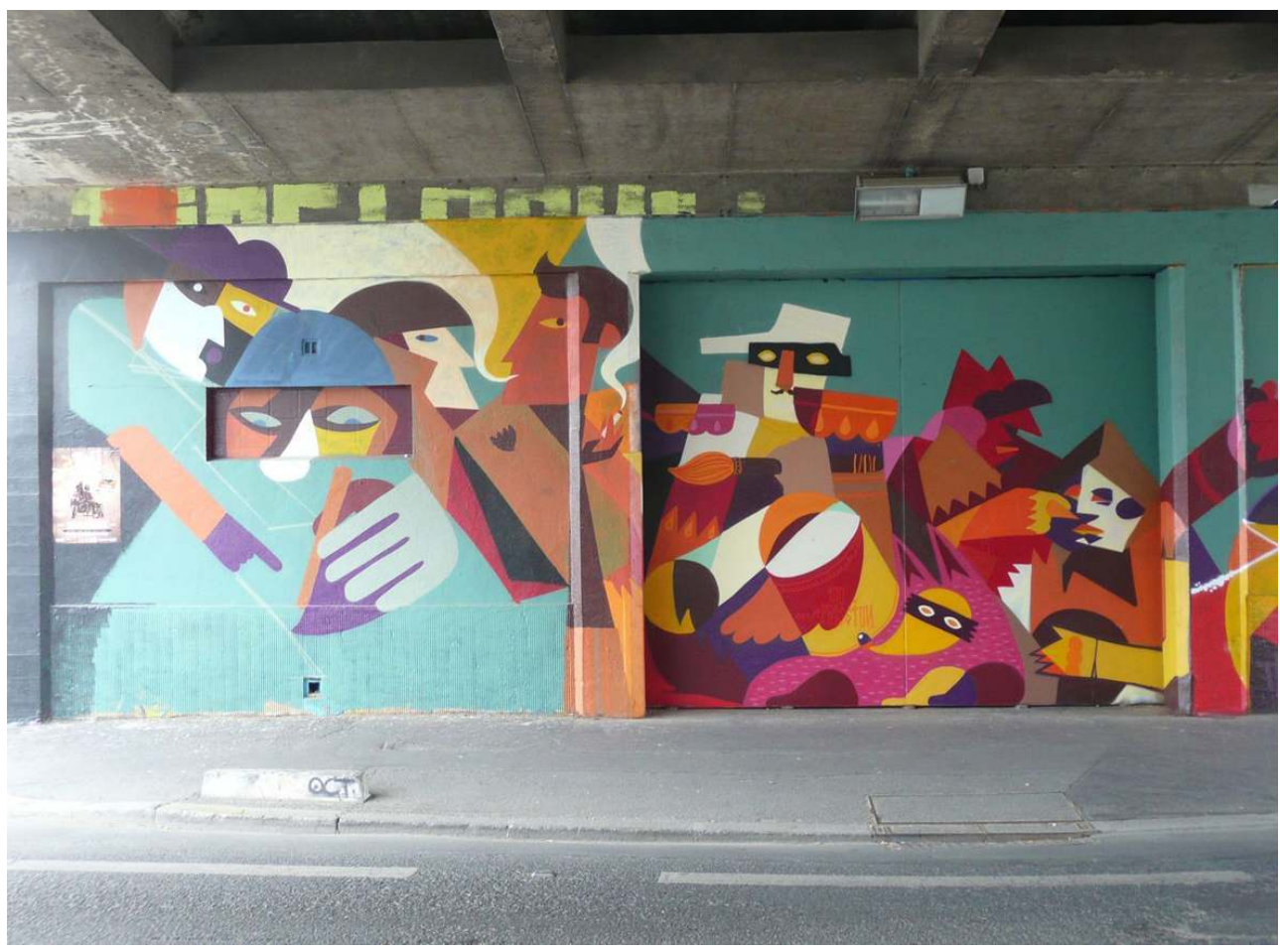

Nantes, Pont Lu. Graf en juin 2011.

PHOT. DAVY, CHRISTIAN. @ CHRISTIAN DAVY, 2011. 
Figure 7

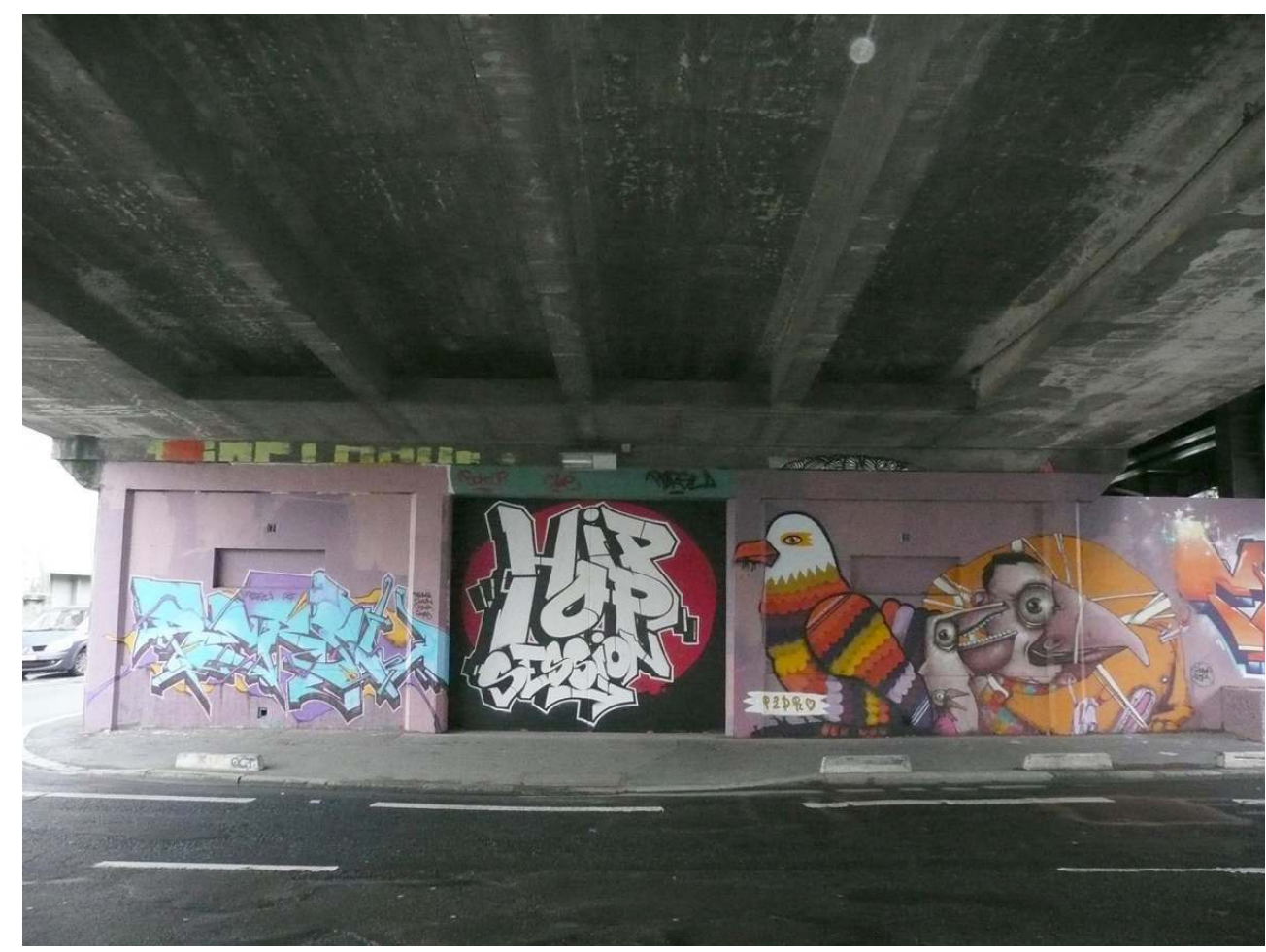

Nantes, Pont Lu. Graf en décembre 2011.

PHOT. DAVY, CHRISTIAN. @ CHRISTIAN DAVY, 2011.

\section{Les édifices conservant de la peinture murale}

19 Quelle que soit leur destination, leur type ou leur propriété, toutes les catégories d'architecture ont pu recevoir un décor de peinture murale à une époque ou à une autre.

\section{Le statut des édifices}

Les édifices conservant de la peinture murale sont majoritairement de propriété publique. L'écart entre statut public et privé est de 15 points, mais ce résultat doit être pondéré et peut être considéré comme réduit. En effet, le cahier des charges orientait les prospecteurs en priorité vers les édifices publics, ceux de propriété privée étant inclus dans la mesure où leurs peintures murales étaient déjà connues des professionnels du patrimoine, ce qui aurait pu aboutir à une différence plus ample. Cependant la relative faiblesse de cet écart est explicable par la qualité de la prospection et par le grand nombre de décors peints recensés sur les murs extérieurs des propriétés privées, accessibles de la voie publique, tels les publicités, les enseignes figurées, les trompe-l'œil ou les grafs. Ce phénomène est particulièrement marqué dans le département de la LoireAtlantique où les peintures murales de statut privé sont majoritaires. 


\section{Lieux cultuels et lieux profanes}

21 Les prospecteurs devaient identifier la nature profane ou cultuelle de l'édifice. L'information nécessitait parfois d'être précisée au niveau du bâtiment, car certains édifices présentent simultanément les deux catégories. Ainsi, une abbaye est constituée de lieux de culte : église et chapelle, et de plusieurs bâtiments à usage profane : logis abbatial, réfectoire, cellier, hôtellerie des hôtes, etc. De même, les demeures laïques, comme le château ou le manoir, disposent parfois d'un lieu de culte, tel l'oratoire ou la chapelle. Le distinguo entre le bâtiment cultuel où se célèbre un office religieux et les autres s'avère indispensable pour analyser les messages de la représentation figurée en fonction du contexte architectural. $60 \%$ (1542 occurrences) des peintures murales ont été repérées dans les édifices cultuels, toutes périodes confondues (fig. $\left.\mathbf{n}^{\circ} \mathbf{8}\right)$. Il s'agit principalement d'églises paroissiales. Ce constat est cependant à pondérer, car le domaine privé ne constituait pas une priorité de la prospection. 82 \% (399 sur 486) des peintures murales médiévales sont conservées dans des lieux de culte. Même si les peintures murales civiles étaient vraisemblablement aussi courantes que les décors religieux, le renouvellement plus rapide du décor des édifices profanes a entraîné leur disparition. La plus ancienne d'entre elles date du XII ${ }^{e}$ siècle et a été repérée dans une maison angevine. La disparité de conservation apparaît moins aiguë aux autres périodes historiques : $61 \%$ (247 sur 405) de peintures murales religieuses à l'époque moderne et 59 \% (1 180 sur 2007) à l'époque contemporaine. À l'intérieur de cette dernière période historique, les écarts sont particulièrement marqués. 90 \% (967 sur 1 069) de la peinture murale du XIXe siècle a été exécutée dans un édifice de culte. Ce chiffre baisse fortement et régulièrement ensuite : $51 \%$ (512 sur 1007$)$ au XXe et $6 \%$ (19 sur 322$)$ au XXI ${ }^{e}$ siècle. 
Figure 8

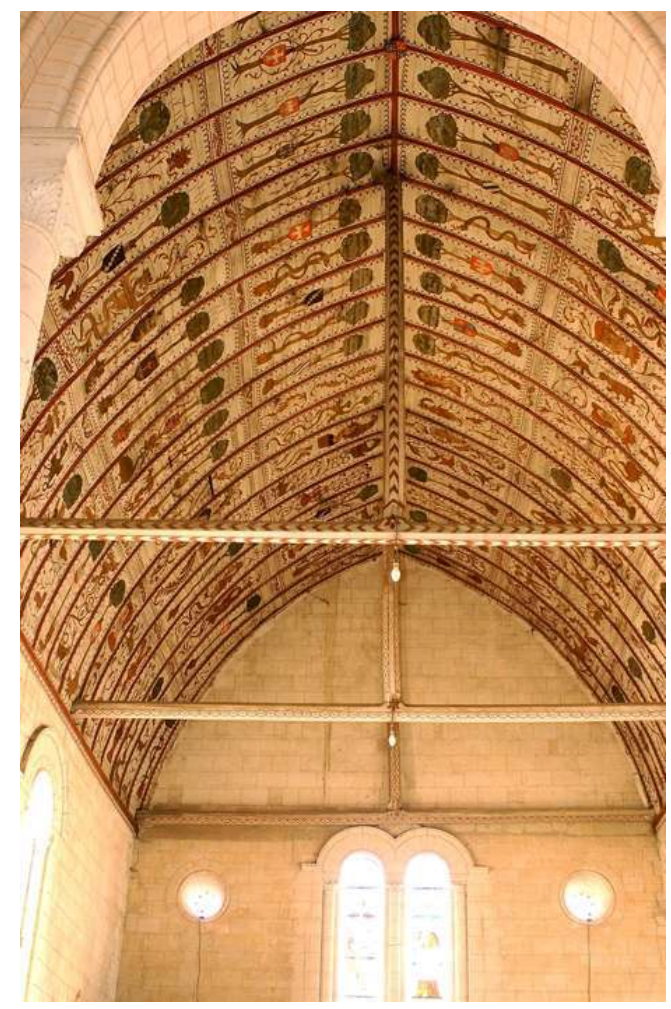

Fontaine-Guérin (Maine-et-Loire), église paroissiale Saint-Martin de Vertou. Vue d'ensemble du décor du lambris de couvrement de la nef.

Phot. Rousseau, Bruno. ( C Conseil général du Maine-et-Loire, 2004. IVR52_20044900588NUCA

La répartition géographique présente quelques disparités entre les départements. La présence de la peinture murale dans des édifices cultuels est régulièrement majoritaire à l'exception du département de Loire-Atlantique où le rapport entre cultuel et profane s'inverse. La Vendée présente un rapport plus équilibré qui reste favorable aux édifices cultuels. Cette inégalité territoriale tient notamment au grand nombre de murs extérieurs privés et peints, phénomène déjà évoqué dans le chapitre précédent.

\section{Les types d'édifices}

Les édifices conservant des peintures murales ont été répartis dans trois catégories. Les édifices religieux - église paroissiale, chapelle, abbatiale et prieurale - constituent un premier groupe majoritaire regroupant près de $60 \% \mathrm{du}$ corpus. Ce constat est conforme aux prévisions, car la quasi-totalité des églises paroissiales appartiennent aux communes depuis la loi de 1905 et ont donc été systématiquement visitées.

La deuxième catégorie rassemble les édifices ayant vocation à recevoir du " public » hors du contexte cultuel. Elle est constituée de mairies, écoles, salles polyvalentes, salles de sports, stades, musées, théâtres et commerces. Lui ont été rattachés les édifices industriels, les châteaux d'eau et les transformateurs. Avec $15 \%$ du corpus, elle forme un groupe peu développé. La faiblesse de ce chiffre est plutôt inattendue : ainsi le nombre de mairies décorées d'une peinture murale est inférieur à $1 \%$. Ce phénomène est par ailleurs 
amplifié par la forte proportion des peintures murales réalisées sur les murs extérieurs d'édifices privés. Ce groupe présente cependant des créations de grand intérêt.

Les demeures - maison, immeuble, château, manoir et ferme - constituent le troisième groupe. Cette catégorie appartient de manière quasi exclusive au domaine privé. Avec 26 $\%$, les demeures forment une part importante du corpus. Ce chiffre reflète toutefois de manière inégale la réalité du terrain. Les peintures murales exécutées sur les murs extérieurs des demeures privées sont mieux prises en compte que les peintures murales réalisées à l'intérieur.

La répartition géographique apparaît globalement homogène avec quelques variations. Les peintures murales repérées sur les commerces, les édifices industriels et les écoles sont beaucoup plus nombreuses dans les deux départements du littoral (205 occurrences en Loire-Atlantique et Vendée) que dans les trois de l'intérieur (62 occurrences en Maineet-Loire, Mayenne et Sarthe). La Loire-Atlantique montre d'autres écarts par rapport aux moyennes régionales. Deux d'entre eux doivent être considérés comme significatifs. Le taux - $29 \%$ - des églises paroissiales ornées de peintures murales est nettement inférieur à ceux des quatre autres départements variant entre $45 \%$ et $51 \%$. Ce résultat pourrait provenir de conditions de prospection différentes ou/et de réalités historiques qui restent à déterminer. Il est possible d'évoquer l'hypothèse d'une position spécifique du diocèse de Nantes au XIX ${ }^{e}$ siècle concernant la décoration des églises paroissiales. La seconde variation concerne le nombre de peintures murales réalisées sur les immeubles. Il atteint $16 \%$ en Loire-Atlantique pour seulement $1 \%$ pour le reste du territoire. Elle apparait comme l'une des conséquences de la production contemporaine peinte sur les murs extérieurs des propriétés privées évoquée dans les chapitres précédents.

\section{La datation des peintures murales}

\section{Périodes historiques et édifices}

La méthode de saisie des informations recueillies lors de la prospection permet de déterminer le nombre d'édifices conservant de la peinture murale par époque. Un édifice peut présenter des peintures de plusieurs périodes historiques, c'est pourquoi le total des datations atteint $113 \%$. En revanche, cette méthode ne permet pas de déterminer le nombre exact de décors peints à une époque donnée. En effet, plusieurs peintures murales réalisées dans une même période historique au sein d'un même édifice ne sont comptabilisées qu'une unique fois.

28 La répartition entre les trois périodes historiques présente une forte disparité. La grande majorité $(78 \%)$ des peintures murales a été réalisée à l'époque contemporaine, tandis que $19 \%$ d'entre elles l'ont été à l'époque médiévale et $16 \%$ à l'époque moderne. Si les époques médiévale et moderne sont faiblement représentées en pourcentage, le nombre absolu de leurs peintures murales est loin d'être négligeable : en plus de 480 occasions, des peintures murales du Moyen Âge ont été rencontrées et en plus de 400 fois d'autres de l'époque moderne.

\section{L'époque médiévale ( $\mathrm{XI}^{\mathrm{e}}-\mathrm{XV}^{\mathrm{e}}$ siècles)}

Les plus anciennes peintures murales médiévales remontent assurément au $\mathrm{XI}^{\mathrm{e}}$ siècle et peut-être au $X^{e}$ siècle avec les fragments trouvés en fouilles archéologiques dans la crypte 
de l'église abbatiale d'Évron en Mayenne. Les plus récentes, dont les auteurs sont encore imprégnés de la culture médiévale, ont été exécutées au début du XVI ${ }^{e}$ siècle.

Le nombre des peintures murales de cette époque augmente au fur et à mesure des siècles. Une centaine d'entre elles réalisée entre l'an mille et les années 1200 est d'expression romane (fig. $\mathbf{n}^{\circ} \mathbf{9}$ ). La couleur prime sur le trait et chaque image est peinte au sein d'un vaste programme. Les autres, près de 400 , sont d'esprit gothique. Parmi ces dernières, celles réalisées aux XIII ${ }^{e}$ et XIV ${ }^{e}$ siècles témoignent de la prééminence du trait sur la couleur, tandis qu'au $\mathrm{XV}^{\mathrm{e}}$ siècle le développement de la piété individuelle favorise la réalisation d'images isolées ou regroupées au sein de programmes de faible ampleur. Un unique édifice laïc conserve de la peinture murale romane tandis qu'un peu plus de 80 châteaux, manoirs, logis ou même simples maisons sont ornés de peintures murales gothiques.

Figure 9

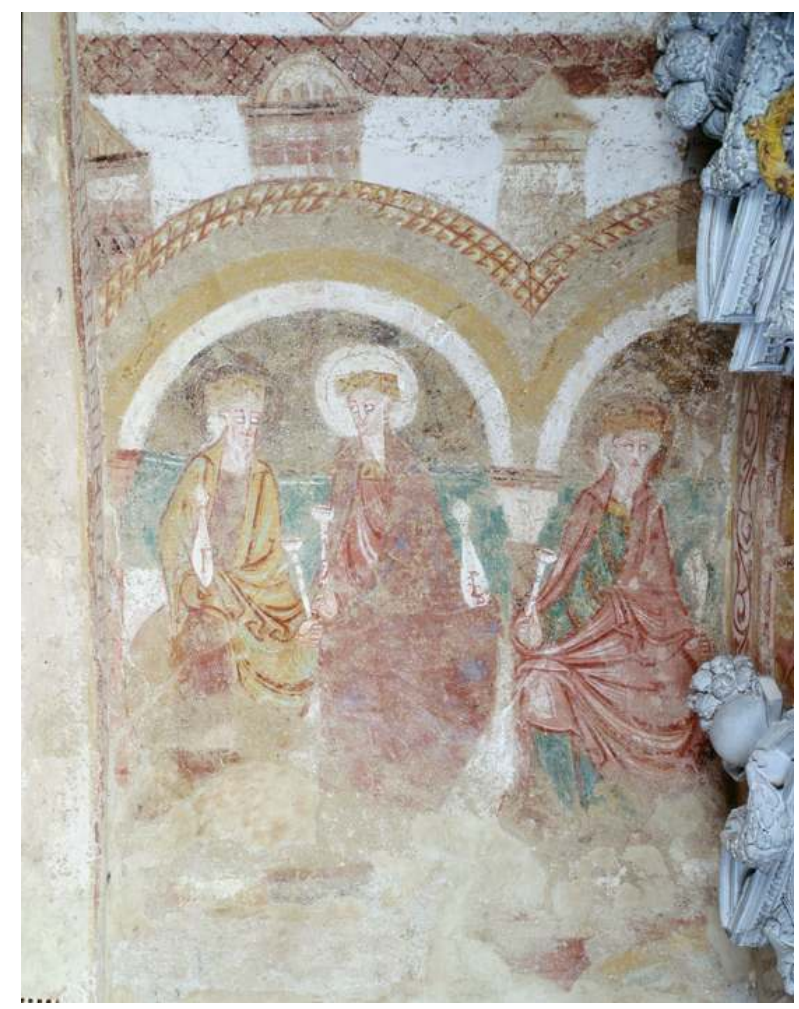

Laval (Mayenne), chapelle Notre-Dame de Pritz, chœur. Vieillards de l'Apocalypse.

Phot. Giraud, Patrice. (c) Conseil régional des Pays de la Loire, service du patrimoine, 1995. IVR52_19955300022XA

31 Les peintures murales médiévales sont inégalement conservées sur le territoire régional. Elles le sont principalement dans les trois départements de l'intérieur : Maine-et-Loire (23 $\%, 145$ occurrences), Mayenne (18\%, 82 occurrences) et Sarthe (35,8\%, 196 occurrences). Le fort pourcentage constaté en Sarthe provient de la méthode de prospection approfondie mise en place dans le nord de ce département. La présence des peintures murales du Moyen Âge est faible en Vendée ( $9 \%, 50$ occurrences) et ponctuelle en LoireAtlantique (3\%, 13 occurrences). Une explication de cette forte disparité provient de l'important mouvement de reconstruction des églises paroissiales mis en place par les autorités ecclésiastiques dans la seconde moitié du XIX ${ }^{e}$ siècle. Sauf dans le cas 
exceptionnel d'une dépose et d'une repose, comme au Loroux-Bottereau où les peintures murales du XII ${ }^{e}$ siècle ont été ainsi sauvegardées de la destruction du prieuré, la disparition de l'ancienne église entraîne obligatoirement celle des peintures murales. Seule une église sur cinq environ antérieure au XIX ${ }^{\mathrm{e}}$ siècle est actuellement conservée en Loire-Atlantique.

\section{L'époque moderne (XVIe-XVIII siècles)}

405 peintures murales ont été réalisées entre le XVI et le XVIII ${ }^{e}$ siècle, ce qui représente $16 \%$ du corpus. Malgré un cahier des charges limitant la prospection aux édifices de propriété publique, le nombre des décors civils conservés dans les châteaux, manoirs, logis ou demeures de notables est d'ores et déjà élevé : 159 œuvres ont été répertoriées. Ce nombre ne cesse d'augmenter avec les découvertes réalisées après l'achèvement de la prospection, tel ce plafond peint entre 1626 et 1657 à Laval. Il confirme l'intérêt porté au décor peint par les hommes vivant à cette période, alors que celle-ci était jusqu'à récemment considérée comme réfractaire à cet art. Les peintures religieuses restent dominantes. L'iconographie évolue avec les préconisations du Concile de Trente. La représentation de saint Christophe disparaît au profit de celle des saints Roch, Sébastien et sainte Barbe par exemple. Le répertoire s'élargit également avec le développement des décors profanes. La représentation du végétal dans ses diverses formes, du bouquet de fleurs au paysage se répand (fig. $\left.\mathbf{n}^{\circ} \mathbf{1 0}\right)$.

Figure 10

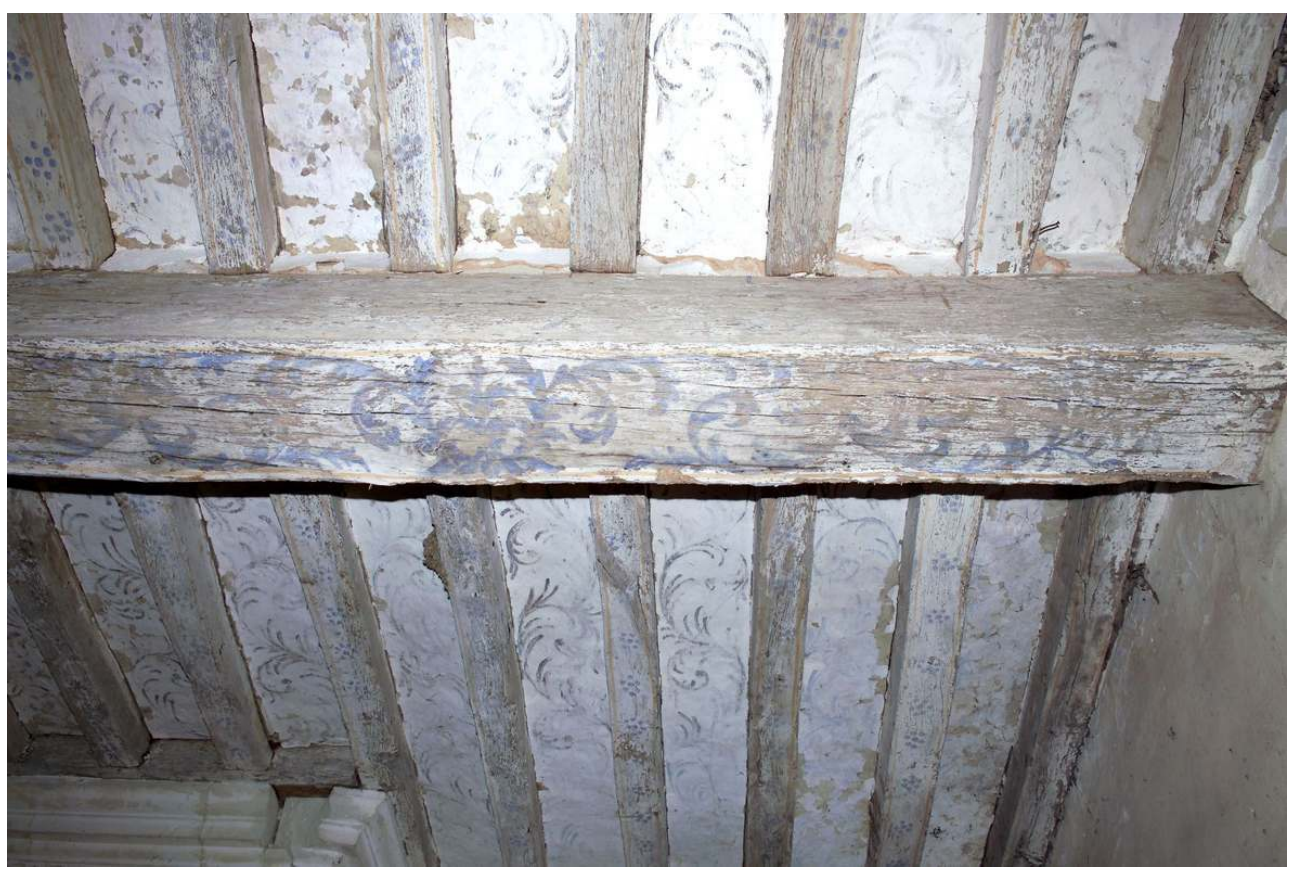

Ligné (Loire-Atlantique), demeure privée. Plafond peint de la salle à l'étage.

Phot. Pillet, Denis. (c) Conseil régional des Pays de la Loire, service du patrimoine, 2003. IVR52_20034400347NUCA

33 La répartition territoriale apparaît inégale. Près d'un quart du corpus des peintures murales de la Sarthe a été réalisé à l'époque moderne. Le Maine-et-Loire avec 109 occurrences se place aussi au-dessus de la moyenne régionale. La Vendée conserve 67 peintures murales de cette époque. Ce nombre en forte progression est comparable à 
celui de la Mayenne où 71 décors ont été peints entre le $\mathrm{XVI}^{\mathrm{e}}$ et le $\mathrm{XVIII}{ }^{\mathrm{e}}$ siècle. En revanche les 25 peintures murales de cette période ne représentent qu'une faible part en Loire-Atlantique. Les raisons avancées pour la période médiévale restent valables pour la période moderne.

\section{L'époque contemporaine (XIXe-XX|e siècles)}

Plus de 2000 édifices présentent au moins une peinture murale réalisée à l'époque contemporaine. Cette intense activité connaît quelques variations au cours de cette période. La majorité (53\%, 1069 occurrences) a été produite au XIX ${ }^{\mathrm{e}}$ siècle (fig. $\left.\mathbf{n}^{\circ} \mathbf{1 1}\right)$, près d'un tiers (30\%,602 occurrences) au XX siècle - la première moitié étant un peu plus productive (331 peintures murales) que la seconde (271) -, tandis que d'ores et déjà 322 peintures murales réalisées au cours de la première décennie du XXI ${ }^{\mathrm{e}}$ siècle ont été repérées. $25 \%$ du corpus ont été peints dans les soixante dernières années.

Figure 11

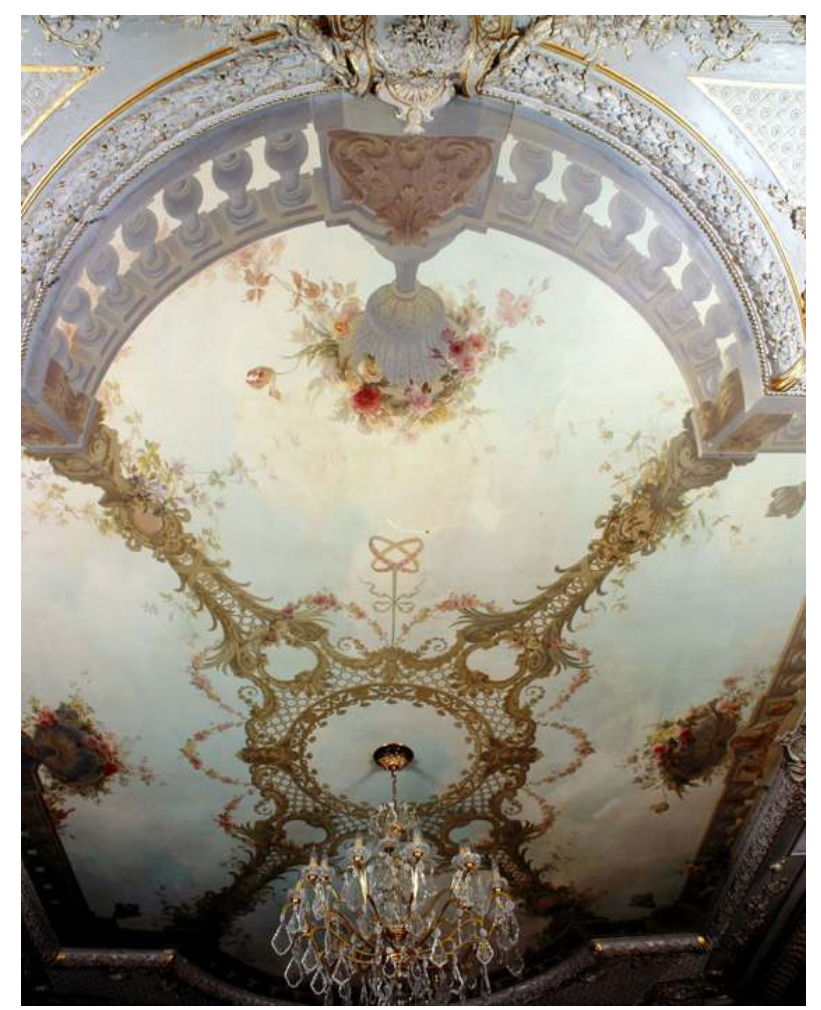

Fontenay-le-Comte (Vendée), La Sablière. Plafond peint, vers 1885.

Phot. Giraud, Patrice. ( C Conseil régional des Pays de la Loire, service du patrimoine, 1996. IVR52_19968500226XA

La production évolue fortement au cours de la période. Au XIX ${ }^{\mathrm{e}}$ siècle, elle est essentiellement axée autour des décors religieux conservés à l'intérieur des édifices de culte. $\mathrm{Au} \mathrm{XX} \mathrm{XX}^{\mathrm{e}}$ siècle, elle commence à occuper les murs extérieurs. Des réclames sont peintes le long des routes, des publicités puis des trompe-l'œil apparaissent sur les immeubles dans la seconde moitié du siècle. Les grafs fleurissent sur toutes sortes de murs à la fin du XX et au début du XXI ${ }^{\mathrm{e}}$ siècle, sans que les décors peints à l'intérieur des édifices disparaissent. 

sur l'ensemble du territoire. Quelques nuances apparaissent en fonction des tranches historiques opérées à l'intérieur de la période. L'importance de la production du XIX siècle est générale, même si elle semble moindre en Loire-Atlantique. En revanche, la répartition des peintures murales de la seconde moitié du $\mathrm{XX}^{\mathrm{e}}$ et du début du $\mathrm{XXI}^{\mathrm{e}}$ siècle est nettement inégale sur le territoire. Celle-ci est concentrée, dans la proportion des deux tiers, en Loire-Atlantique et en Vendée. Elle est dense sur le cordon littoral, sur le cours de la Loire et aussi dans les centres urbains comme Nantes et la Roche-sur-Yon, mais aussi Angers. Elle est plus diffuse sur le reste du territoire régional.

\section{La représentation}

\section{Les types de décors}

La représentation en peinture murale est répartie en trois catégories. Le décor ornemental joue un rôle essentiellement décoratif, encore que dans certaines circonstances il peut être chargé de sens symbolique. Le répertoire des motifs ornementaux est inspiré des formes géométriques, du monde végétal ou de l'architecture. Les trois sources peuvent être associées dans un même décor. La deuxième catégorie regroupe les peintures murales à figurations isolées qui représentent des êtres vivants ou fantastiques, des objets ou des paysages. Elles sont à la fois décoratives et signifiantes. Enfin, dans le troisième type, la peinture murale est dite historiée, car elle illustre une action en une ou plusieurs scènes. Ces dernières sont souvent intégrées dans une série qui constitue un cycle. Le message est sous-jacent à l'histoire racontée en images. Une peinture murale combine souvent deux ou trois de ces catégories de représentation : le total dépasse ainsi largement les $100 \%$.

La production de décors ornementaux est majoritaire. De plus, elle est aussi importante que celle des deux autres catégories réunies. La répartition des types de décors au niveau régional est inégale. La Loire-Atlantique présente moins de peintures murales ornementales, la Mayenne et le Maine-et-Loire une plus faible proportion de décors à figurations isolées et un taux de décors ornementaux plus élevé. Enfin, le Maine-et-Loire conserve un taux de peintures historiées moindre que dans les autres départements.

\section{Le décor ornemental}

Le décor ornemental est présent dans près des deux tiers des édifices à peinture murale. Son utilisation régulière et dense entre le $\mathrm{XI}^{\mathrm{e}}$ siècle et le $\mathrm{XXI}^{\mathrm{e}}$ siècle témoigne de la place essentielle que l'ornement occupe dans la peinture murale. Il souligne les lignes de force de l'architecture, concrétise l'organisation des images entre elles, sans oublier la portée symbolique qu'il peut posséder (fig. $\mathbf{n}^{\circ} \mathbf{1 2}$ ). L'architecture constitue sa principale source d'inspiration. Les représentations de maçonneries en appareil de pierres de taille, dites faux-appareil, complétées de claveaux d'arcs, de niches architecturées, de retables, de pinacles et autres éléments architectoniques ont été rencontrées dans près des deux tiers des décors ornementaux. Signalée dans 784 cas, la représentation d'appareil de pierres de taille est essentiellement un décor d'édifice cultuel ( $92 \%$ des cas). Elle couvre souvent les murs intérieurs et la voûte. Quelques châteaux en conservent parfois sur leurs façades. Bien que connue régionalement dès le $\mathrm{XII}^{\mathrm{e}}$ siècle et représentée régulièrement par la suite, elle a été majoritairement réalisée au XIX ${ }^{\mathrm{e}}$ siècle. Dès la fin du Moyen Âge, une 
polychromie sur les clefs de voûte agrémentée de motifs végétaux ou géométriques, ainsi que d'armoiries peintes, lui est fréquemment associée.

Figure 12

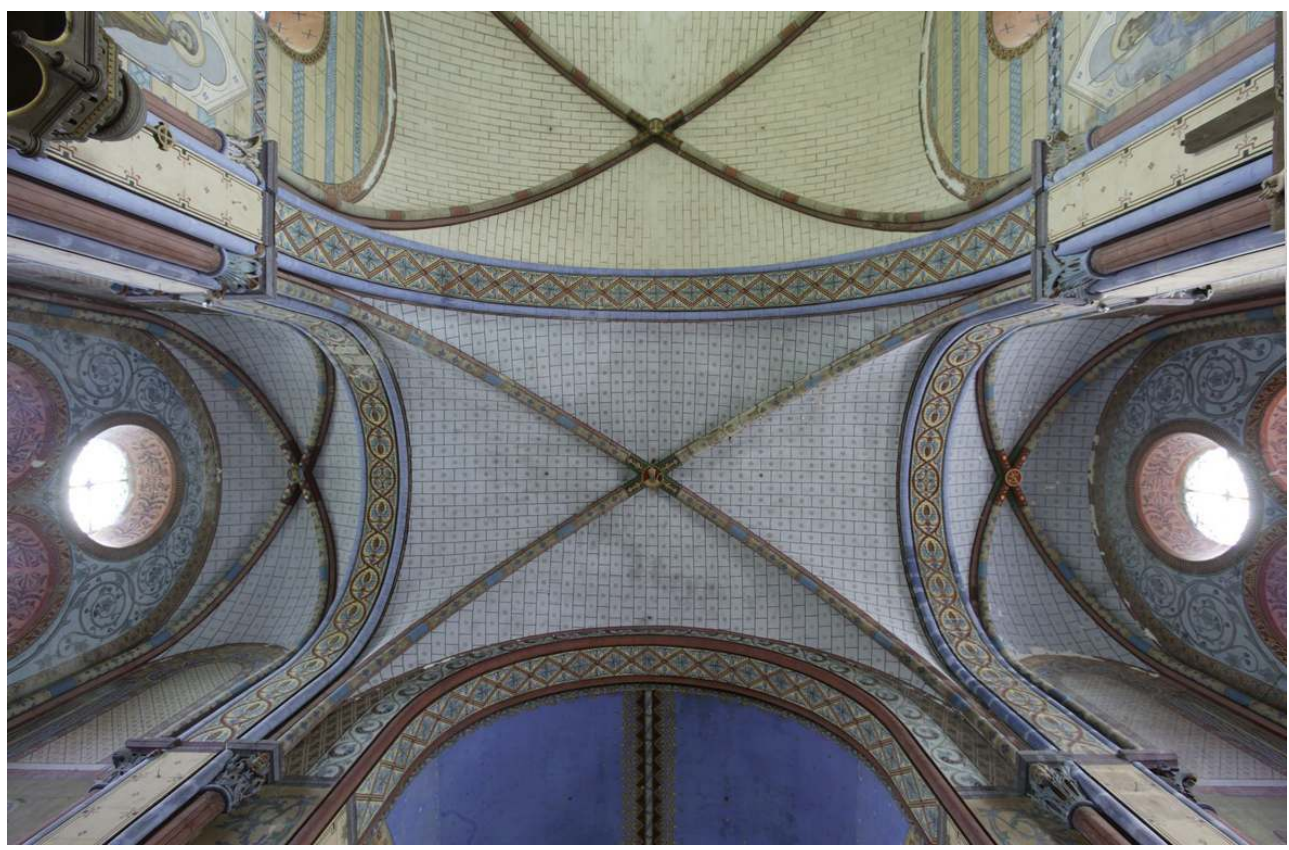

Saint-Martin-du-Limet (Mayenne), église paroissiale Saint-Martin. Vue en contre plongée de la croisée de transept.

Phot. Giraud, Patrice. (C) Conseil régional des Pays de la Loire, service du patrimoine, 2005. IVR52_20055300293NUCA. Les motifs peuvent être traités avec un réalisme saisissant, reflétant les manières de peindre de l'époque moderne ou contemporaine, ou à l'inverse dans une stylisation extrême, et cela à toutes les périodes historiques.

Le répertoire géométrique a moins inspiré les peintres décorateurs. Ce type de motif a été rencontré dans moins de $50 \%$ des cas. Au Moyen Âge, ils sont répétés à l'infini aussi bien dans les décors couvrants qu'en série ou en frise dans les bordures. Aux périodes moderne et contemporaine, ils sont plutôt employés dans les bordures. chaque période historique. Leur variation à la moyenne régionale est faible ; seuls deux écarts paraissent significatifs. Le décor végétal est moins représenté au Moyen Âge et inversement à l'époque moderne qui, par ailleurs, a moins prisé le décor à motifs architecturés.

\section{Le décor avec figurations}

Un peu plus d'un tiers des sites à peinture murale présente une ou plusieurs figurations. L'iconographie est variée, bien que les thèmes religieux soient fort présents. Cette constatation s'accorde avec le fait que les édifices cultuels représentent $60 \%$ du corpus des édifices peints prospectés. 494 personnages (le Christ, la Vierge, les saints ou les anges) et 330 motifs ( 282 croix de consécration, 43 monuments aux morts de la paroisse et 19 références aux instruments de la Passion) évoquent la religion chrétienne. Les 39 
figures mentionnées comme symboles se réfèrent aussi bien au domaine religieux qu'à la mythologie ou à la Franc-maçonnerie. 112 personnages profanes ont été représentés. Il s'agit d'hommes célèbres - de Napoléon ou Charrette à Jules Verne, Jacques Tati ou Bob Marley -, ou de personnages imaginaires issus des légendes ou de la bande dessinée - de Calliope et Uranie à Gaston Lagaffe. Les animaux, parfois des héros de bande dessinée, constituent le sujet dans 84 figurations. Le paysage, réel ou imaginaire (fig. $\mathbf{n}^{\circ} \mathbf{1 3}$ ), a inspiré les décorateurs en 45 occasions et les objets dans 96 cas. Enfin, 15 trompe-l'œil ont été notés dans cette rubrique sans autres précisions, ainsi que 10 litres seigneuriales, enduit posé en bande et supportant des armoiries.

Figure 13

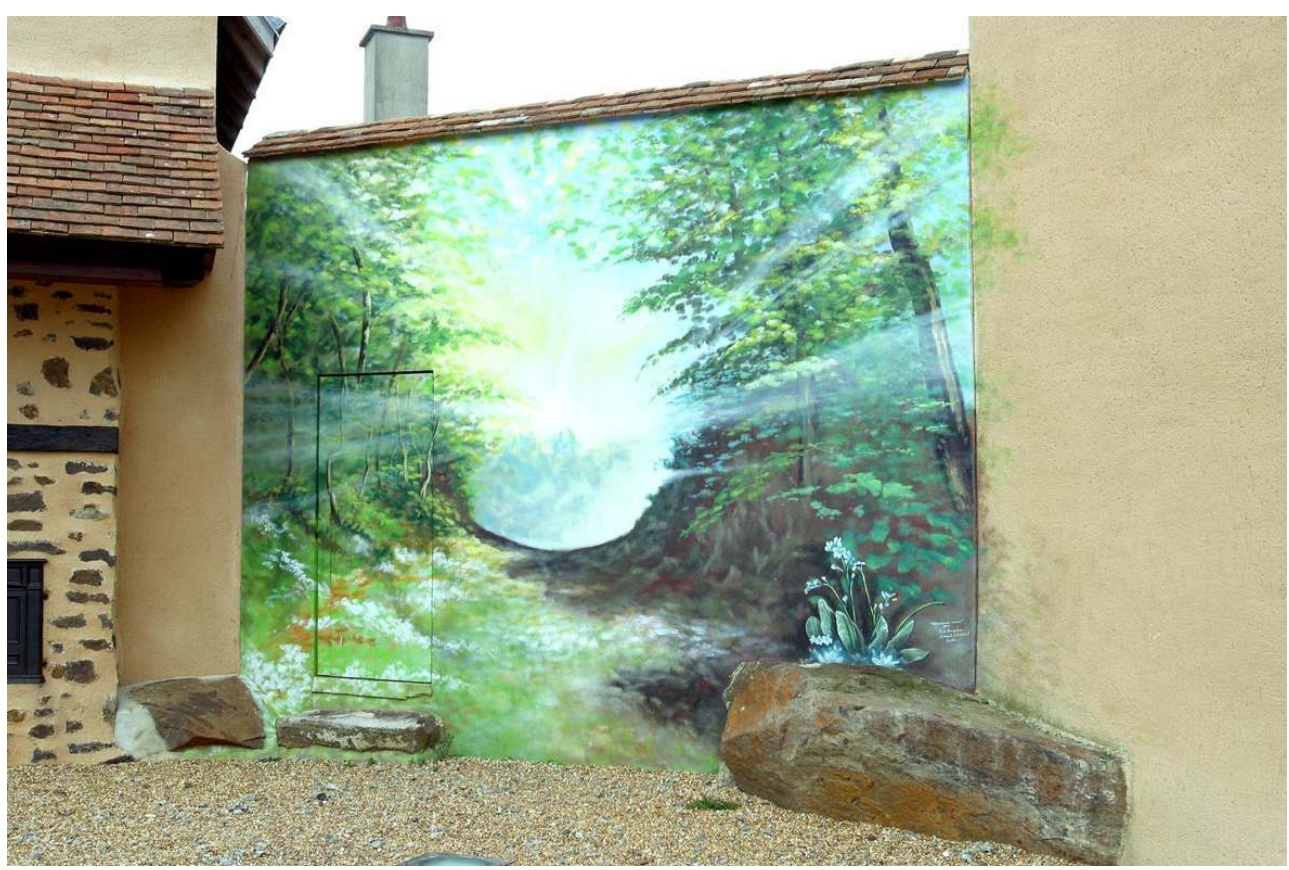

La Chapelle-Saint-Fray (Sarthe), point de rendez-vous des randonneurs au centre du village. Éblouissement matinal.

Phot. Giraud, Patrice. (c) Conseil régional des Pays de la Loire, service du patrimoine, 2004. IVR52_20047200363NUCA

Lorsque des figurations profanes ont été repérées dans des édifices cultuels, elles prennent alors une signification religieuse. À l'inverse, des représentations de saints ou de scènes religieuses ne sont pas rares dans des édifices laïcs où elles gardent leur signification première. L'aspect religieux domine la figuration de manière quasi-totale au Moyen Âge, un peu moins à l'époque moderne et reste tout de même très présente à l'époque contemporaine. Ce n'est que dans les soixante dernières années que le rapport religieux - laïc s'inverse en faveur de la figuration profane.

Près d'un quart $(23 \%)$ des décors avec figurations ont été peints au Moyen Âge, un peu moins (18 \%) à l'époque moderne et une forte majorité (77 \%) à l'époque contemporaine. Comme pour l'ornemental, il n'est pas rare qu'un même édifice présente des figurations d'époques différentes. Ces proportions sont similaires à celles observées pour le décor ornemental. 


\section{Le décor avec scènes : le décor historié}

Un tiers des édifices à peinture murale conserve un décor comportant une ou plusieurs scènes. Ce type de représentation peut être isolé et présente alors une action unique. Il peut également en accompagner d'autres à l'intérieur d'un cycle racontant différents épisodes d'une histoire. La répartition historique des peintures murales historiées est assez proche des deux catégories précédentes avec toutefois une légère augmentation de leur présence au Moyen Âge $(28 \%)$ et à l'époque moderne $(20 \%)$ et une légère diminution à l'époque contemporaine (72\%).

L'iconographie religieuse est majoritaire (52\%). La moitié de ces représentations raconte les actions des saints et dans près des deux-tiers de ces cas, plusieurs épisodes de leurs vies. De même, près de la moitié présente un des épisodes de la vie du Christ, ou l'une de ses actions (fig. $\mathbf{n}^{\circ} \mathbf{1 4}$ ). Enfin, un quart présente des scènes liées à la Vierge. Une moitié de ces peintures murales à iconographie religieuse a été réalisée au Moyen Âge, un quart à l'époque moderne et plus d'une autre moitié $(60 \%)$ à l'époque contemporaine. De nouveau, le total est nettement supérieur à $100 \%$ : plus d'un site conserve des peintures historiées religieuses peintes à des époques différentes. Dans la tranche historique la plus récente, il s'agit essentiellement ( $88 \%$ ) de peintures murales exécutées au XIXe et dans la première moitié $\mathrm{du} \mathrm{XX}$ siècle. Seules 34 peintures murales religieuses ont été créées entre 1950 et 2011.

Figure 14

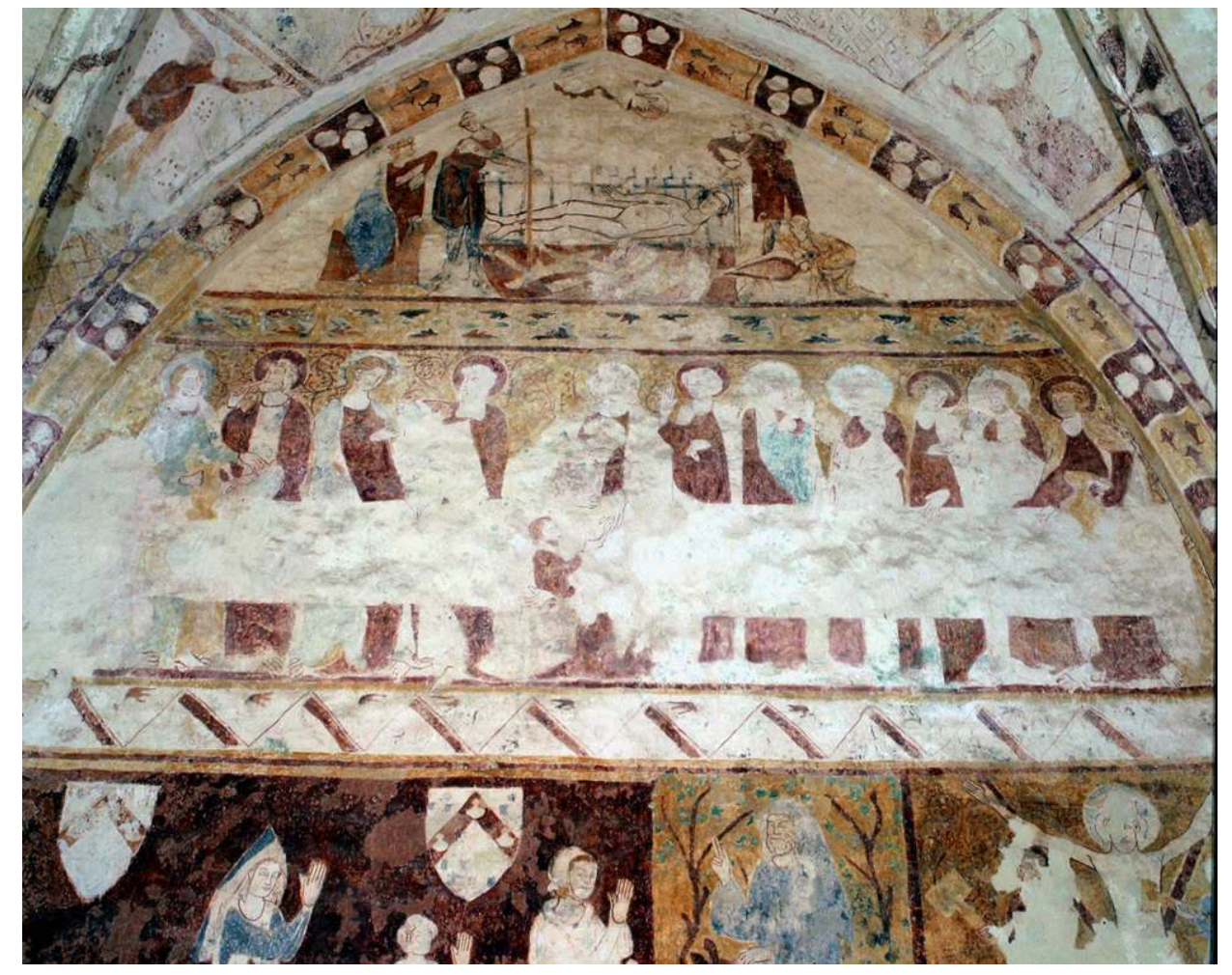

Mesnard-la-Barotière (Vendée), ancienne église paroissiale Saint-Christophe, chœur. Vue d'ensemble du mur nord.

Phot. Giraud, Patrice. (c) Conseil régional des Pays de la Loire, service du patrimoine, 2000. IVR52_20008500423XA 

murale sur deux (48 \%) (fig. $\left.\mathbf{n}^{\circ} 15\right)$ conserve une ou plusieurs inscriptions ; un peu plus même en Loire-Atlantique. En revanche, les différents types d'inscriptions retenus à l'origine ont été très inégalement rencontrés. La moitié d'entre elles dépassent les $10 \%$, tandis que d'autres n'atteignent pas $1 \%$. Les huit principaux types d'inscription ont été répartis en trois catégories. Elles se rapportent à l'homme, à l'œuvre ou à l'aspect religieux de l'œuvre. Les inscriptions évoquant l'homme sont les plus courantes. Les armoiries $(27,8 \%)$ renvoient souvent au commanditaire de la peinture murale ou alors à une autorité, le plus souvent morale. Les signatures $(23,9 \%)$ gardent la mémoire de l'auteur. Dans la majorité des cas, il s'agit de l'exécutant, qu'il soit un artiste peintre ou une entreprise de décoration. La seconde catégorie rassemble les inscriptions liées à l'œuvre. La date de réalisation (18,1 \%), le titre de la représentation (15,6 \%) aident à une meilleure connaissance de l'image ou de la peinture murale. La réclame, puis la publicité qui vante un produit en en reproduisant le nom (15\%) ont été rattachées à cette catégorie. L'aspect religieux définit la dernière catégorie. Il s'agit d'inscriptions liturgiques (15,3\%), de monogrammes (13,5\%), le plus souvent IHS ou MA, mais aussi de commentaires $(10,6 \%)$, souvent inspirés des textes sacrés, qui amplifient le message de l'image. Il arrive exceptionnellement que ce dernier type d'inscription se rapporte à une œuvre profane. 


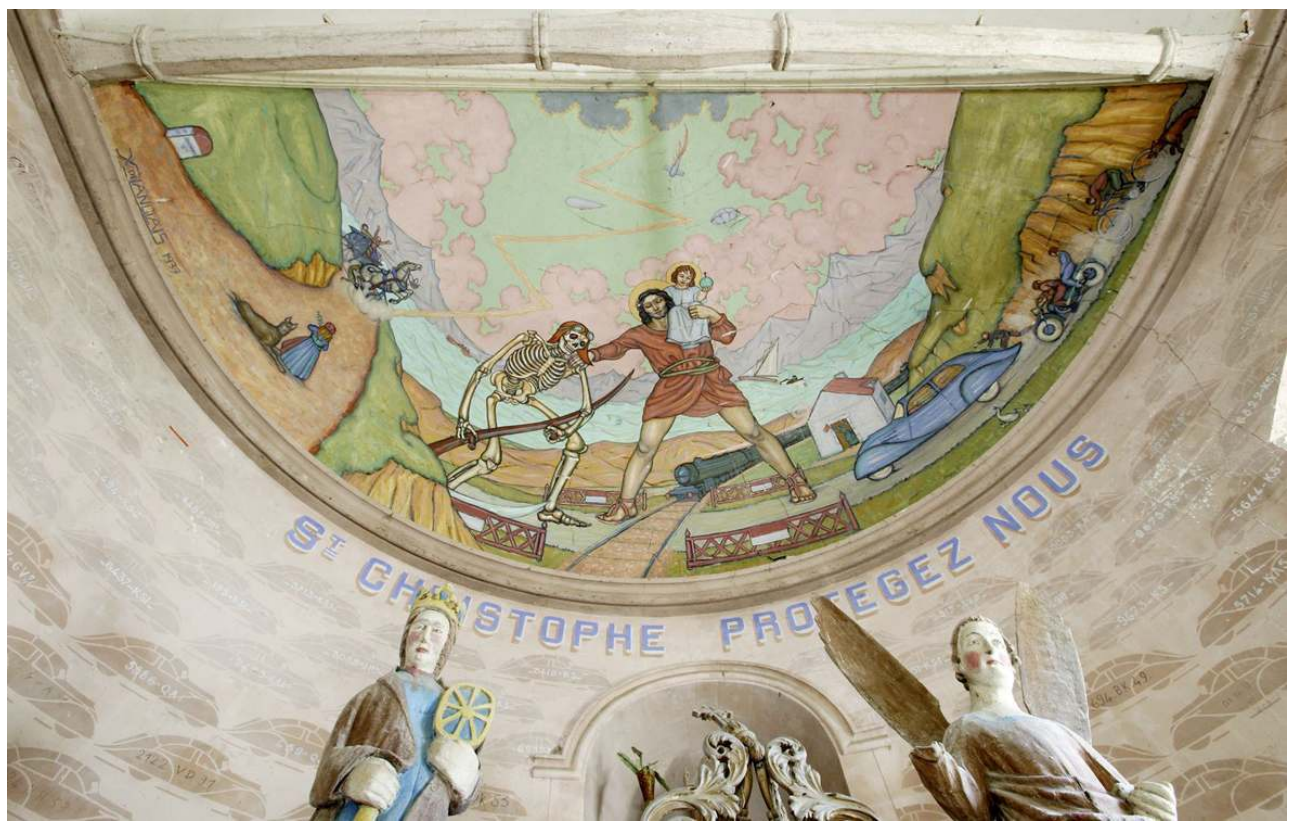

La Boissière (Mayenne), ancienne église Saint-Christophe. Saint Christophe arrête le bras de la mort. Phot. Giraud, Patrice. (c) Conseil régional des Pays de la Loire, service du patrimoine, 2005. IVR52_20055300254NUCA

\section{Deux cas spécifiques : les armoiries et les signatures}

Considéré à tort comme un privilège de la noblesse, le port d'armoiries était ouvert à tous : les historiens connaissent des armoiries portées par des paysans dès le XIII ${ }^{e}$ siècle. Phénomène identitaire de l'Ancien Régime (fig. $\mathbf{n}^{\circ} \mathbf{1 6}$ ), les armoiries connaissent une nouvelle phase de développement au XIX ${ }^{e}$ siècle : la majorité des armoiries accompagnant les peintures murales régionales date de cette période. Les armoiries ont été majoritairement rencontrées dans les trois départements de l'intérieur. Les armoiries médiévales sont conservées dans leur quasi-totalité en Sarthe, en Maine-et-Loire et en Mayenne. À l'époque moderne, l'aire de représentation des armoiries s'étend au territoire de la Vendée et de manière très ponctuelle à celui de la Loire-Atlantique. À l'époque contemporaine, les représentations d'armoiries sont repérées sur l'ensemble du territoire régional avec toutefois une densité moindre dans les deux départements du littoral. 


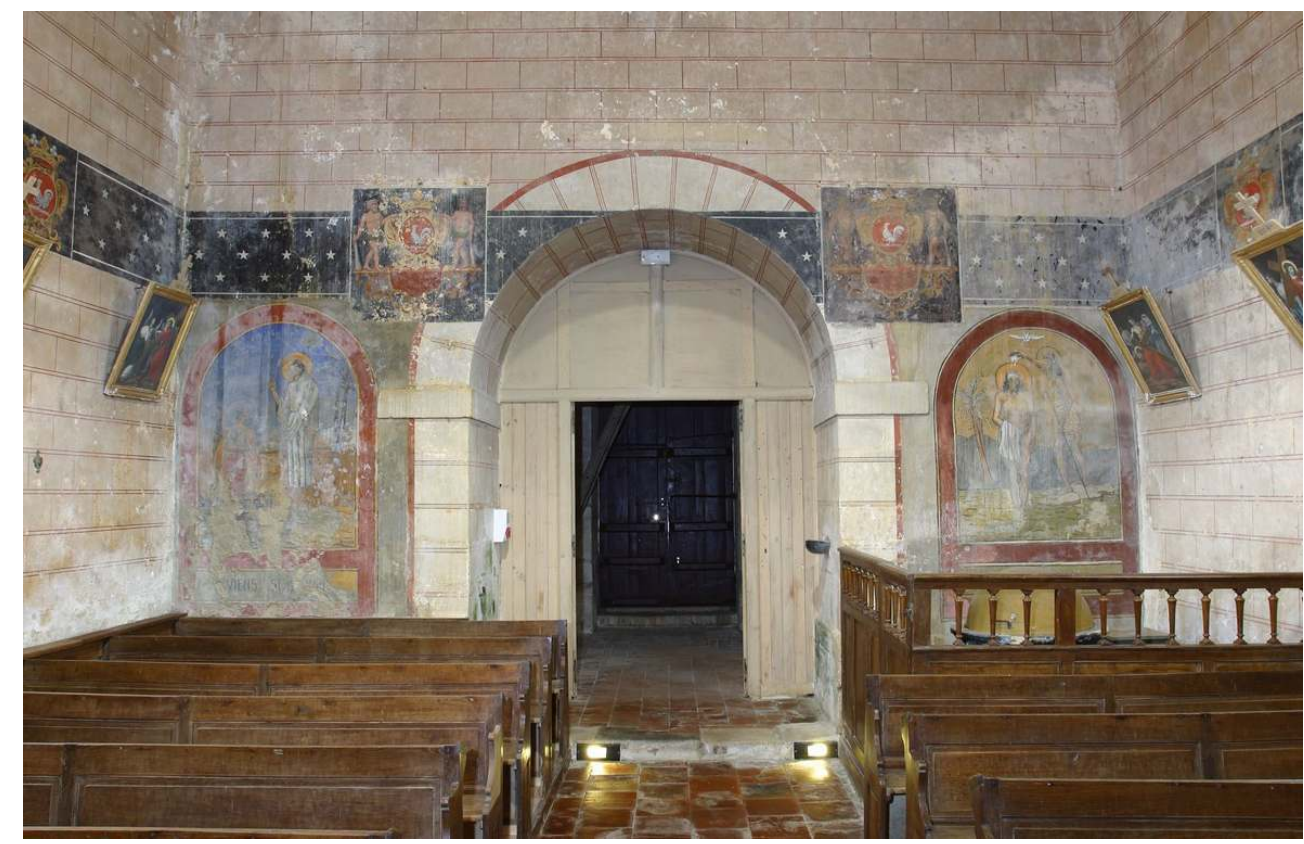

Courgains (Sarthe), église paroissiale Saint-Pierre. Nef, mur occidental orné de la litre seigneuriale aux armes des Le Riche.

Phot. Giraud, Patrice. (c) Conseil régional des Pays de la Loire, service du patrimoine, 2003. 7200165NUCA

Les signatures sont quasi absentes à l'époque médiévale et à peine présentes à l'époque moderne. Cela ne constitue pas une surprise, la peinture murale ne pratiquant que peu l'individualisation de l'artiste ou de l'artisan décorateur. Ce mouvement s'inverse à l'époque contemporaine : la présence d'une signature s'y élève à $15 \%$. La progression au sein de cette période historique est nette : elle passe de $7 \%$ au XIXe siècle à $27 \%$ pour la période des soixante dernières années.

Les 293 signatures repérées par les prospecteurs concernent 172 peintres ou entreprises de peinture murale. 31 peintres ou entreprises ont signé à trois reprises au moins. Ils apparaissent dans le tableau ci-dessous, ordonnés en fonction du nombre d'occurrences. Ces peintres opèrent principalement sur le territoire de leur département. Ils débordent occasionnellement sur l'un des départements voisins. Quatre peintres possèdent une réputation nationale, voire internationale : Jules Dauban qui fut membre de l'Institut, Jules Lenepveu, directeur de l'Académie de France à Rome et auteur du plafond de l'Opéra de Paris, Élie Delaunay, membre de l'Académie des Beaux-Arts, participe aux décors de l'Opéra de Paris, de l'Hôtel de Ville de Paris et du Panthéon. Tous les trois ont pratiqué leur art au XIX ${ }^{\mathrm{e}}$ siècle. Gaston Chaissac, artiste du XXe siècle, est l'un des principaux créateurs du mouvement nommé l'Art brut. Vient ensuite une cohorte d'artistes de bonne ou d'excellente réputation dont la carrière est restée essentiellement régionale. Parmi eux, il est possible de citer les frères Paul et Albert Lemasson, Pierre Bouchaud, Louis Renouard, Henri Simon ou Roger Blaquière. Ces peintres avaient également le souci de dater leurs œuvres. À l'exception de l'entreprise Positiv'Aéro qui a été repérée en treize occasions en Vendée et en Maine-et-Loire, les dix peintres les plus productifs ont travaillé entre 1850 et 1950. 


\section{Des orientations pour la recherche et la valorisation de la peinture murale}

En matière de peinture murale, l'hypothèse d'un projet de recherche global bute immédiatement sur l'ampleur considérable du corpus établi. Il apparaît donc indispensable d'établir des cadres pour délimiter le champ des futures investigations dans ce domaine. Du nombre confronté au type et au sujet d'étude se dégage un premier panel de propositions de recherche. La quantité d'œuvres repérées doit en effet être suffisamment élevée pour assurer la représentativité de l'étude. À l'inverse, certaines œuvres, d'ordre exceptionnel ou emblématique, peuvent également être abordées dans le cadre d'une étude particulière.

L'analyse des résultats de la prospection a mis en évidence des répartitions chronologiques et territoriales diverses. Parfois une période historique ou un secteur géographique spécifique est concerné, parfois la thématique englobe l'ensemble de la période ou du territoire. Dans certains cas, l'étude s'attache à un aspect local et dans d'autres elle touche à des problématiques actuellement à la pointe de la recherche en France ou en Europe. Elle peut être également menée en complémentarité avec des travaux engagés dans d'autres domaines. Enfin, la prospection a fait émerger un thème de recherche inédit : le monument aux morts de la paroisse. Assurément, les résultats de ces futurs travaux participeront au développement culturel, scientifique, pédagogique, économique et touristique des Pays de la Loire.

La Région des Pays de la Loire a identifié la peinture murale comme un sujet patrimonial prioritaire et agit en conséquence. Ainsi, elle a mené à son terme l'étape de la prospection pour établir et analyser le corpus des peintures murales repérées. Elle engage dès à présent le second volet de l'opération par la détermination de thèmes de recherche approfondie d'intérêt régional, la programmation de certains d'entre eux et l'établissement de partenariats avec les collectivités territoriales et les institutions intéressées par ces projets.

La médiation constitue un atout pour la recherche scientifique. Il est possible de la conduire de manière à ce que le public puisse s'approprier rapidement ce patrimoine malgré la durée pluriannuelle de certains volets de l'étude. La variété des moyens : oral, écrit, exposition et surtout multimédia dont les vastes possibilités sont adaptées aux spécificités de la peinture murale et à la diversité des publics, permet dans certains cas d'entreprendre la valorisation dès le commencement des études et de placer le public dans un rôle d'acteur ou de collaborateur de la recherche scientifique.

Les onze propositions de recherche scientifique sont présentées sans ordre préférentiel suivant la thématique, le topographique, le chronologique et enfin l'emblématique ou l'exceptionnel.

\section{L'homme et l'espace : la peinture murale ornementale}

L'ornement occupe une place essentielle dans la peinture murale. La prospection a repéré sa présence dans les deux tiers des fiches (1 639 occurrences) quels que soient l'époque historique ou le territoire géographique. Le décor ornemental utilise des motifs inspirés de la géométrie, du monde végétal ou de l'architecture. Malgré son importance 
quantitative, il reste discret visuellement, alors qu'il tient un rôle essentiel pour la structuration du décor et pour souligner les lignes de force de l'édifice. L'un des objectifs de l'étude est une meilleure connaissance d'une part de l'ornement trop souvent relégué à un rôle annexe (fig. $\mathbf{n}^{\circ} \mathbf{1 7}$ ), d'autre part des processus de mise en place des programmes peints et de l'organisation des décors dans l'architecture dans lesquels l'ornement tient un rôle prépondérant. Au-delà, elle permet de mieux comprendre l'action de l'homme sur l'espace architectural.

Figure 17

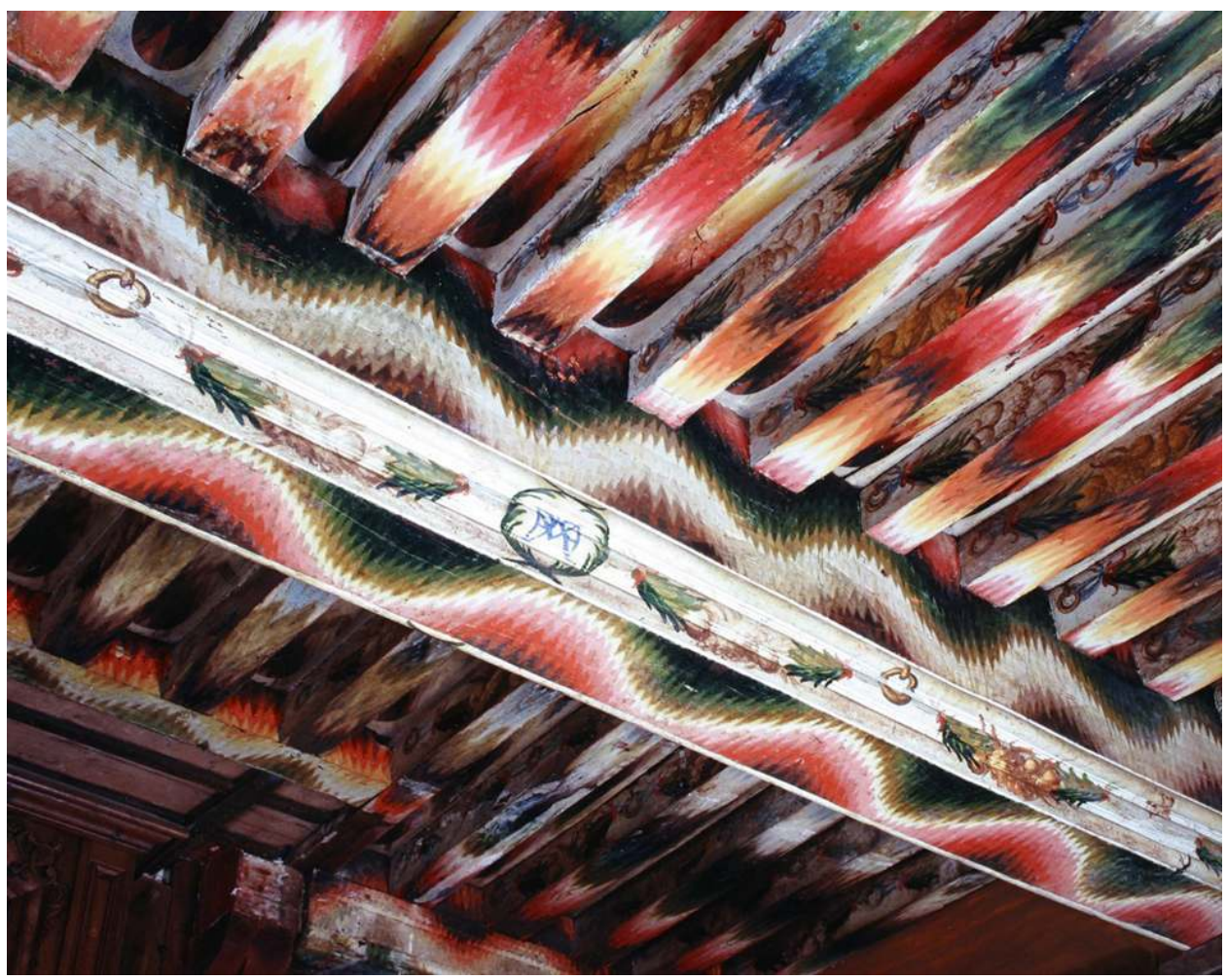

Montourtier (Mayenne), château de Bourgon, plafond. Décor ornemental dit au point de Hongrie. Phot. Lasa, François. (C) Conseil régional des Pays de la Loire, service du patrimoine, 1994. IVR52_20014400618XA IVR52_19945300059XA

\section{La flore et le paysage}

De la fleur stylisée servant d'ornement au paysage réaliste ou onirique, les prospecteurs ont très souvent rencontré l'élément végétal (fig. $\mathbf{n}^{\circ} \mathbf{1 8}$ ). Près de 1000 fiches, qui se répartissent sur l'ensemble du territoire régional, contiennent un décor ornemental à base végétale et plus de 300 fiches signalent une représentation de paysage. Toutes les périodes historiques sont concernées : le végétal symbolique à la période romane ; le passage de la stylisation à la manière réaliste à la période gothique ; l'apparition du paysage et de la scénographie à l'époque moderne ; les paysages réels ou rêvés de l'époque contemporaine. 


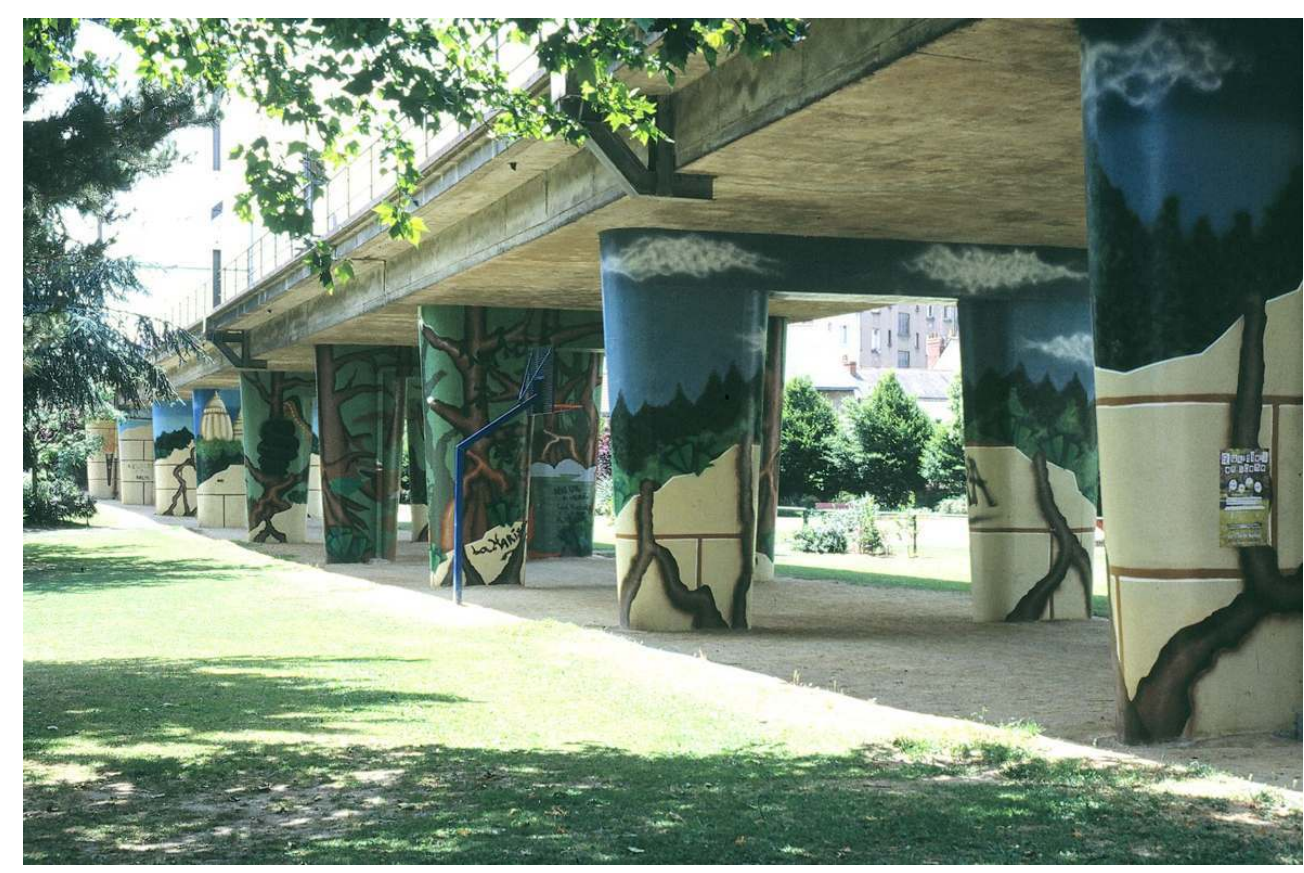

Nantes, Boulevard des Martyrs nantais, pont de chemin de fer. Graf sur le thème de la jungle.

Phot. Pillet, Denis. @ Conseil régional des Pays de la Loire, service du patrimoine, 2002. IVR52_20024400462NUCA

L'étude précise les différentes facettes de la relation que l'homme entretient avec la nature : relation spirituelle, symbolique, ou esthétique. Par ailleurs, cette approche pourrait être mise en parallèle avec l'étude en cours sur les parcs et jardins historiques créés dans la région.

\section{L'Armorial ligérien}

63 La prospection a révélé une richesse inattendue : un armorial peint d'une étonnante ampleur numérique. Plus de 300 peintures murales affichent une ou plusieurs armoiries. Cet armorial est constitué aussi bien des armoiries des communes - remplacées depuis une vingtaine d'années par les logos - que des armoiries des personnes privées ou morales.

64 Étonnamment, la répartition historique atteint son maximum de densité dans la première partie de l'époque contemporaine (1800-1950). Les armoiries des périodes médiévale et moderne sont principalement conservées dans les trois départements de l'intérieur, Maine-et-Loire, Mayenne et Sarthe (fig. $\mathbf{n}^{\circ}$ 19). En revanche, les représentations d'armoiries de l'époque contemporaine, les plus nombreuses, sont réparties sur l'ensemble du territoire régional, avec toutefois une densité légèrement inférieure dans les deux départements du littoral. 
Figure 19

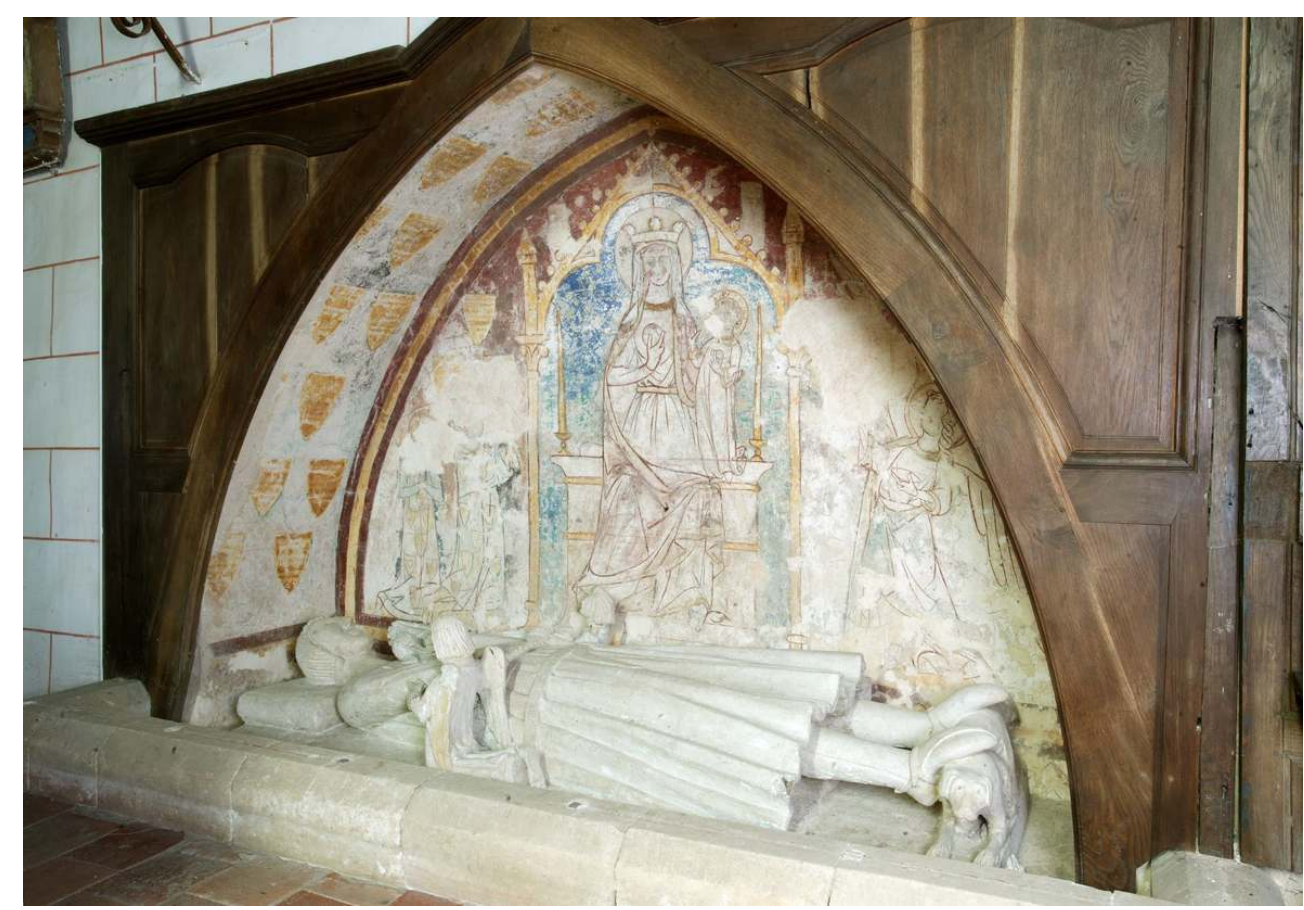

Neuvillette-en-Charnie (Sarthe), église paroissiale Sainte-Gemme. Enfeu aux armes d'un cadet de la famille de Chaources.

Phot. Giraud, Patrice. (C) Conseil régional des Pays de la Loire, service du patrimoine, 2004. IVR52_20047201551NUCA

Si l'étude des armoiries peintes aide à l'identification des familles et des institutions de la région, elle pourrait constituer le départ d'un vaste armorial de l'identité régionale qui serait régulièrement enrichi par les Ligériens eux-mêmes. Cette interaction les transformerait ainsi en acteur ou en collaborateur de la recherche.

\section{Le Graf : de la revendication identitaire à la commande institutionnelle}

La prospection a permis de repérer les dernières « réclames " peintes subsistant le long des routes (184 occurrences). Toutefois, leur étude ne paraît sans doute plus envisageable, du fait de leur état de délabrement avancé et du peu de variété de marques commerciales représentées. Le graf, en revanche, apparaît comme un thème d'étude prometteur (voir fig. $n^{\circ} 5,6$ et 7). Les prospecteurs n'ont pas été en mesure de relever la totalité des grafs en raison du temps imparti qui les empêchait de parcourir tous les lieux et rues susceptibles d'en présenter. Malgré ce handicap, une centaine de fiches montre déjà une créativité évidente. Par ailleurs, une évolution fondamentale est perceptible dans le passage du graf contestataire revendiquant une identité individuelle au graf institutionnel - expression employée par l'un des prospecteurs - issu de commandes officielles de plus en plus fréquentes.

67 L'étude rend compte, d'un côté de l'effort des institutions pour canaliser un mouvement individualiste au profit de la collectivité, au moment où cette création artistique commence à être reconnue et intégrée par le milieu de l'art contemporain et des musées, de l'autre de la création individuelle qui affiche sa liberté d'expression dans l'espace 
public. Elle offre aussi une opportunité de sauvegarde d'un patrimoine immatériel, au moment d'une mutation vécue par ce milieu de production d'œuvres éphémères.

\section{Le décor privé des demeures de notables}

Suivant les prescriptions du cahier des charges, les prospecteurs ont rendu compte d'une manière partielle de l'ampleur des décors intérieurs des demeures privées. Cependant près d'une centaine de peintures murales de l'époque moderne, conservées dans des châteaux, des manoirs ou des maisons bourgeoises, a d'ores et déjà été relevée sur l'ensemble du territoire régional. Ce nombre laisse augurer une grande richesse en ce domaine et des découvertes à venir au fur et à mesure de l'ouverture d'autres demeures (fig. $\mathbf{n}^{\circ} \mathbf{2 0}$ ). Le répertoire thématique est varié, de l'ornemental privilégiant la flore aux images morales. La période contemporaine s'avère aussi intéressante : les styles " néo " marquent la production architecturale et artistique du XIXe siècle et la créativité du XX siècle laisse envisager de belles réalisations à découvrir.

Figure 20

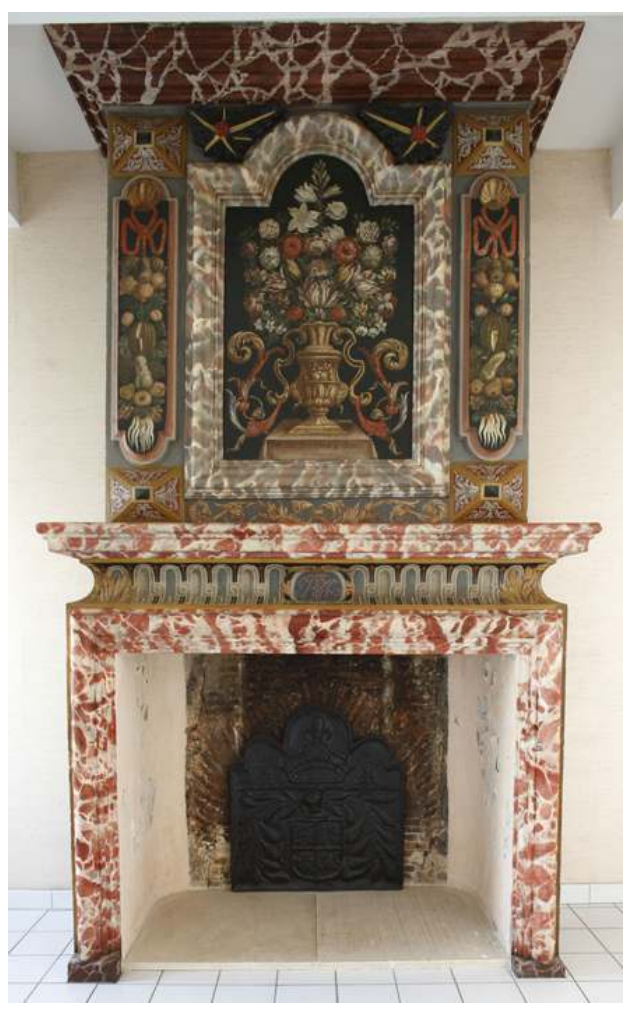

Luçon (Vendée), demeure privée. Cheminée peinte.

Phot. Giraud, Patrice. (c) Conseil régional des Pays de la Loire, service du patrimoine, 2008. IVR52_20088501158NUCA

69 L'un des enjeux de cette recherche est de déterminer dans quelle mesure les mouvements artistiques de la fin du XIX et du $\mathrm{XX}^{\mathrm{e}}$ siècle, qui ont révolutionné la peinture dite de chevalet, auront touché la décoration peinte des demeures privées dans lesquelles la tradition du goût est une composante forte. Par ailleurs, la mise en place de cette étude aura à tenir compte de la volonté de discrétion de la part des propriétaires de ces œuvres. 


\section{Le monument aux morts de la paroisse}

70 La prospection des peintures murales des Pays de la Loire a permis la découverte d'une réalité ignorée : le monument aux morts de la guerre de 1914-1918 de la paroisse. Dans une région durablement marquée par la loi de séparation de 1905, les autorités religieuses ont souvent dressé à l'intérieur des églises la liste des paroissiens tombés au champ d'honneur de la Première Guerre mondiale. Répétitif à cause de la standardisation des stèles en plâtre moulé, fabriquées notamment à Nantes et à Angers, ces monuments aux morts de la paroisse présentent d'incontestables créations de premier ordre en peinture murale (fig. $\mathbf{n}^{\circ} \mathbf{2 1}$ ). Tandis que les communes dressaient des monuments aux morts sur la place publique, un autre monument a été peint dans 43 paroisses, situées dans les cinq départements de la région des Pays de la Loire. La réalisation de cette étude régionale permet de préparer une facette des célébrations du centenaire du déclenchement de la Grande Guerre qui auront lieu en 2014. L'étude de ces œuvres peut ouvrir sur les créations réalisées dans d'autres techniques artistiques (vitrail, sculpture...).

Figure 21

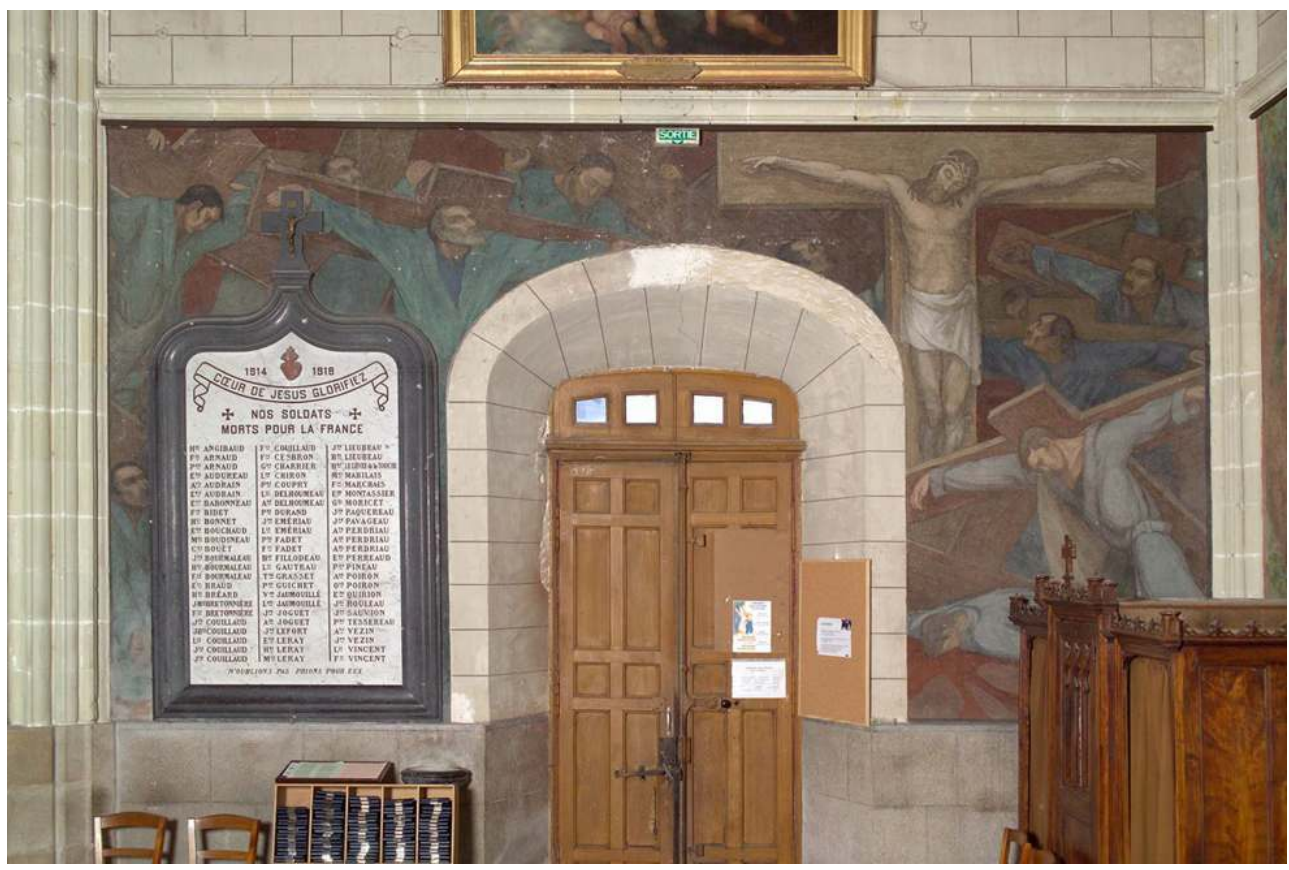

La Haye-Fouassière (Loire-Atlantique), église paroissiale Notre-Dame, bras nord du transept. Le Monument aux morts de la paroisse.

Phot. Pillet, Denis. (C) Conseil régional des Pays de la Loire, service du patrimoine, 2005 IVR52_20054400080NUCA

\section{Entre Loir et Loire}

La zone géographique située " entre Loir et Loire "s'étend sur les départements de Maine-et-Loire et de la Sarthe dans les Pays de la Loire, et de l'Indre-et-Loire, du Loir-etCher, voire de l'Eure-et-Loir dans la Région Centre. Elle présente une densité élevée de peintures murales, ce qui avait déjà été remarqué au XIX ${ }^{\mathrm{e}}$ siècle. Cette production interrégionale s'avère d'une grande homogénéité sur la longue durée allant du Moyen 
Âge au XIXe siècle (fig. $\left.\mathbf{n}^{\circ} \mathbf{2 2}\right)\left(\right.$ fig. $\left.^{\circ} \mathbf{n}^{\circ} \mathbf{2 3}\right)$, tandis que les données comparatives restent à établir pour la période $d u X X^{e}$ et $d u X X I^{e}$ siècle. La mise en place d'une telle étude assoirait la coopération interrégionale dans le domaine de l'inventaire culturel.

Figure 22

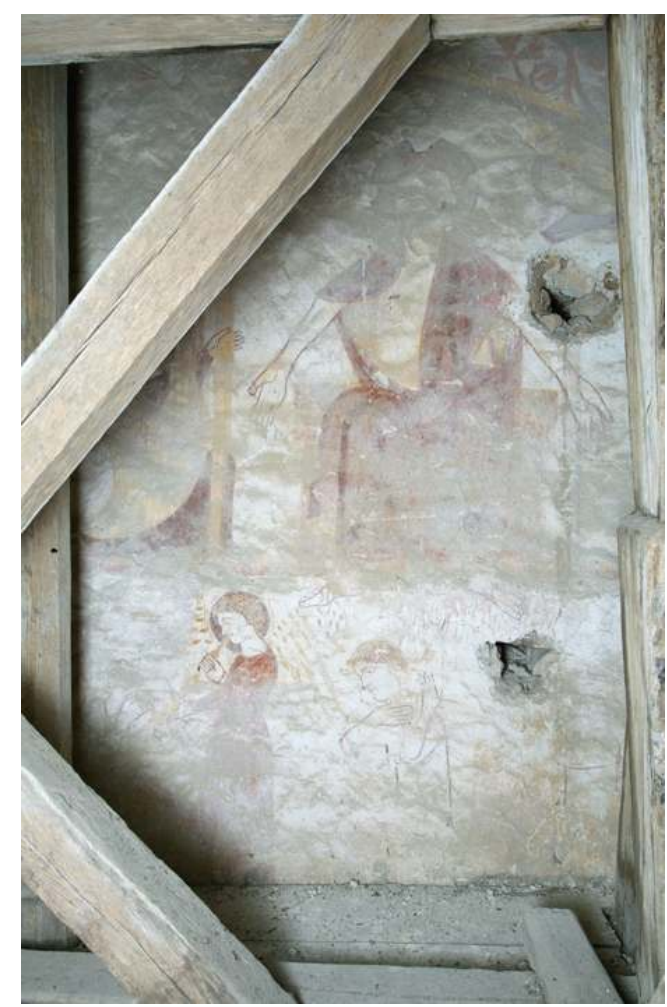

Ruillé-sur-Loir (Sarthe), église paroissiale, nef, mur occidental. Peintures murales cachées par la construction de voûtes à l'époque moderne.

Phot. Giraud, Patrice. ( C Conseil régional des Pays de la Loire, service du patrimoine, 2004 IVR52_20047200492NUCA 
Figure 23

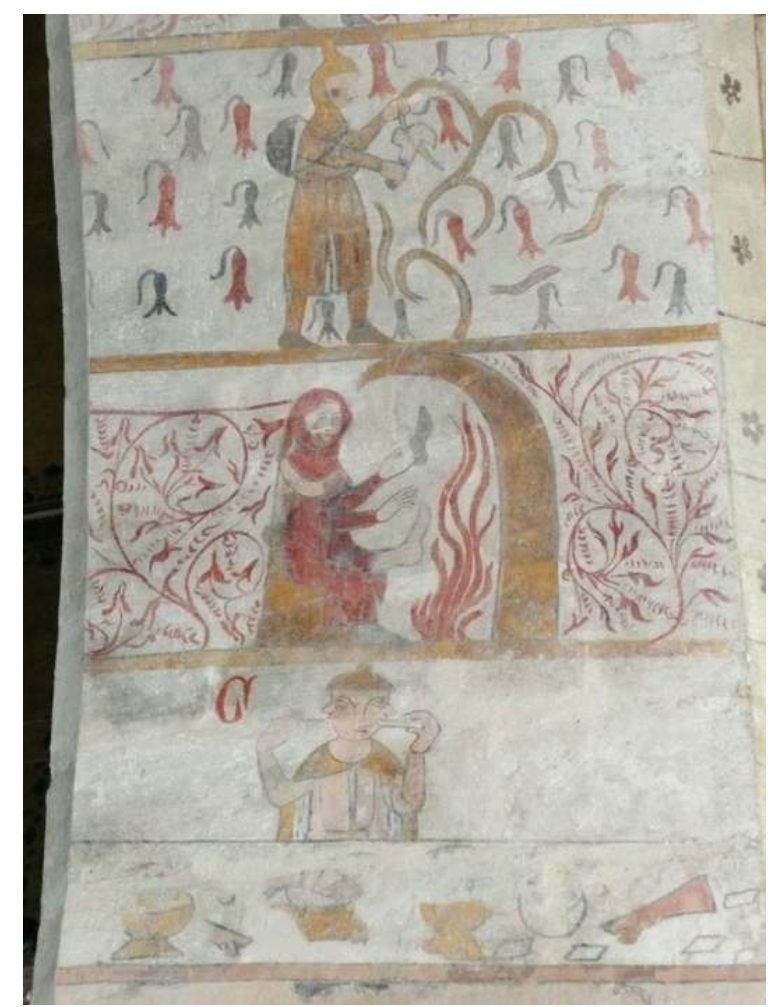

Saint-Christophe-sur-le-Nais (Indre-et-Loire), église paroissiale Saint-Christophe, arcade de passage entre la chapelle nord et le chœur. Calendrier des mois, détail : les mois de janvier, février et mars.

PHOT. DAVY, CHRISTIAN. (c) CHRISTIAN DAVY, 2009.

\section{La création contemporaine dans les départements littoraux $(1950-2011)$}

72 La prospection montre que la Loire-Atlantique et la Vendée, les deux départements littoraux, concentrent les deux tiers de la production de peintures murales des soixante dernières années (435 occurrences). Un grand nombre de ces peintures murales ont été réalisées sur des murs extérieurs. Des personnes privées et des institutions ont manifestement cherché à embellir l'espace public par leur commande à des artistes amateurs et professionnels. Certaines architectures ingrates (château d'eau, transformateur, abri bus, etc.) ont ainsi été ornées (fig. $\left.\mathbf{n}^{\circ} \mathbf{2 4}\right)$. Des façades de maisons ou de commerces l'ont été également. 


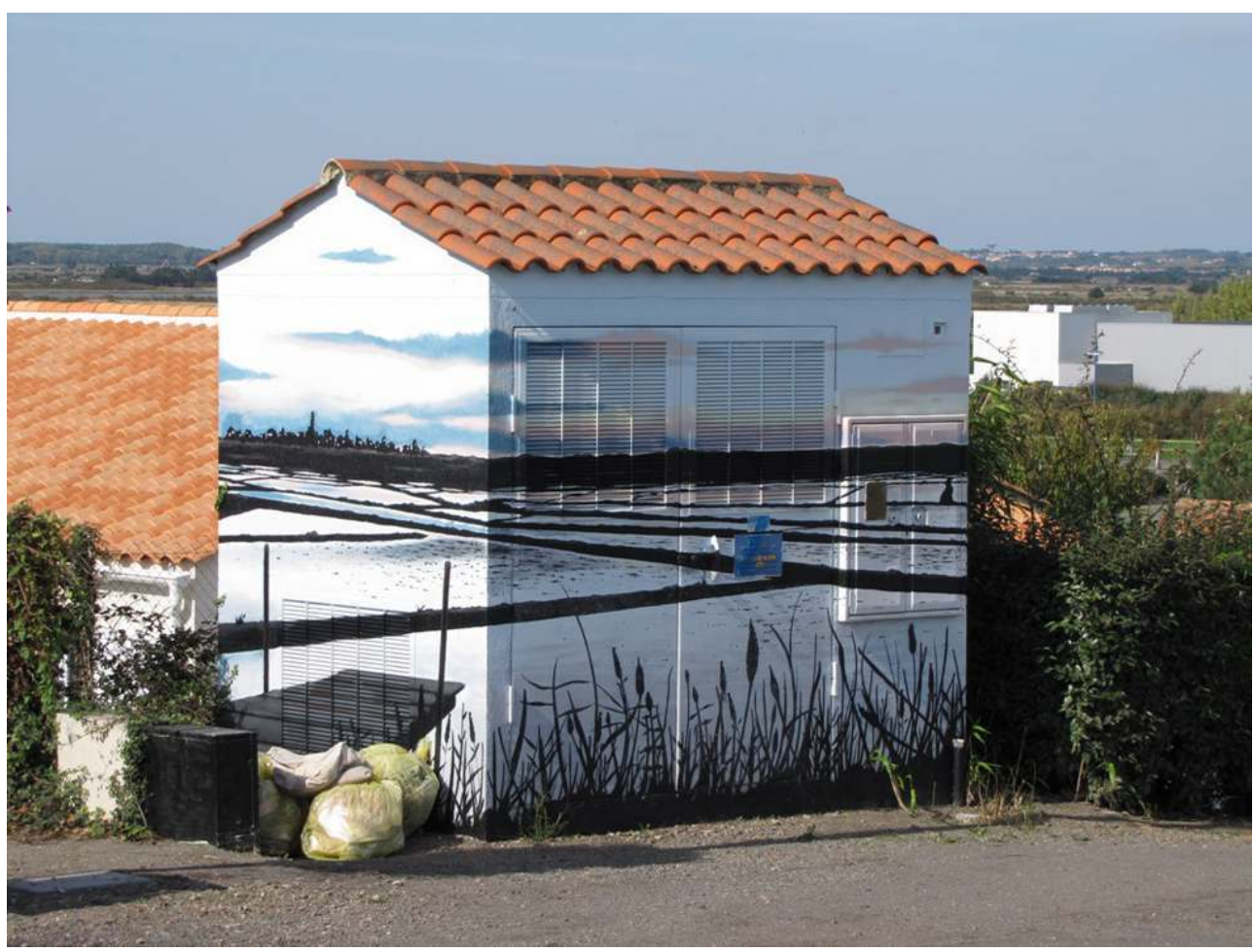

Olonne-sur-Mer (Vendée), transformateur. Paysage de marais.

Phot. Barreau, Pierrick. (C) Pierrick Barreau, 2010.

73 Ce phénomène de répartition inégale sur le territoire ne peut être expliqué a priori. L'identification de sa production à travers les thèmes iconographiques peints, la technique, la qualité artistique ainsi que la connaissance des commanditaires et de leurs motivations permet à terme de comprendre l'originalité de ce mouvement de création local.

\section{Un siècle de création : 1850-1950}

La prospection a révélé une création artistique particulièrement foisonnante entre les années 1850 et 1950. Près des deux tiers des sites (1 394 occurrences) se rapportent au XIX ${ }^{e}$ siècle et à la première moitié du $\mathrm{XX}^{\mathrm{e}}$ siècle (fig. $\mathrm{n}^{\circ} \mathbf{2 5}$ ). Les signatures relevées permettent de sortir des artistes et des œuvres de l'anonymat. Certains de ces peintres avaient une réputation nationale, voire internationale : Jules Dauban fut membre de l'Institut ; Jules Lenepveu, directeur de l'Académie de France à Rome et auteur du plafond de la grande salle de l'Opéra de Paris ; Élie Delaunay, membre de l'Académie des BeauxArts, participe aux décors parisiens de l'Opéra, de l'Hôtel de Ville de Paris et du Panthéon. Tous les trois travaillaient au XIX siècle. Un quatrième, Gaston Chaissac, a vécu au XX siècle et est l'un des principaux membres du mouvement l'Art brut. Vient ensuite une cohorte d'artistes de bonne ou d'excellente réputation. Parmi eux, il est possible de citer Louis Renouard, Albert Vivet, les frères Lemasson, Pierre Bouchaud, Henri Simon ou Roger Blaquière. Ils n'ont pas, pour la plupart, cherché à faire carrière hors du territoire régional. 


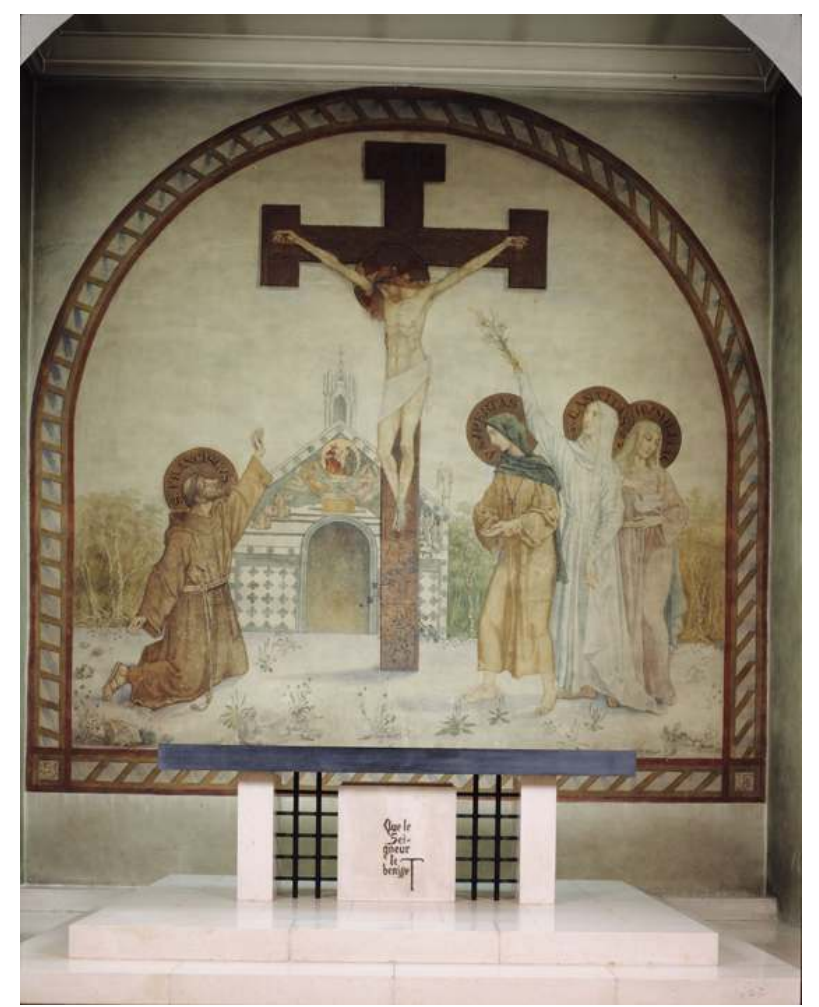

Angers (Maine-et-Loire), couvent des Petites sœurs de saint François, rue Chèvre. Les vertus et saint François au pied du Christ en croix par Louis Yperman, 1931.

Phot. Lasa, François. (C) Conseil régional des Pays de la Loire, service du patrimoine, 1999. IVR52_19994900817VA

La majorité de la production a été repérée dans les lieux de culte de propriété publique en raison du cahier des charges, mais aussi en raison de deux mouvements historiques qui relancèrent de manière dynamique la création artistique. Le premier a vu le jour dans le contexte du vaste débat européen autour de l'art religieux à partir des années 1830 et le second dans les mouvements de réaction à l'art standardisé sulpicien qui fleurirent après la Première Guerre mondiale.

\section{Vers une réévaluation de la peinture murale médiévale?}

76 Les prospecteurs ont repéré près de 500 édifices conservant des peintures médiévales. Ce nombre apparaît particulièrement élevé s'il est comparé à celui enregistré dans les régions qui ont procédé à une semblable évaluation, comme le Poitou ou la Bourgogne. La production repérée s'échelonne entre le $\mathrm{XI}^{\mathrm{e}}$ siècle et le début du $\mathrm{XVI}^{\mathrm{e}}$ siècle. Elle est essentiellement conservée dans les trois départements de l'intérieur des terres : Maineet-Loire, Mayenne et Sarthe. Leur présence est faible en Vendée et ponctuelle en LoireAtlantique.

La production des $\mathrm{XI}^{\mathrm{e}}$ et $\mathrm{XII}{ }^{\mathrm{e}}$ siècles, et celle du XV $\mathrm{XV}^{\mathrm{e}}$ siècle ont été étudiées dans le cadre de recherches universitaires, tandis que celle des XIII ${ }^{\mathrm{e}}$ et des $\mathrm{XIV}^{\mathrm{e}}$ siècles a été pour l'instant délaissée. Pourtant il s'agit d'une époque charnière dans l'évolution des mentalités et de la production artistique. Par ailleurs, la prospection a repéré des peintures murales inédites (fig. $\mathbf{n}^{\circ} \mathbf{2 6}$ ). 


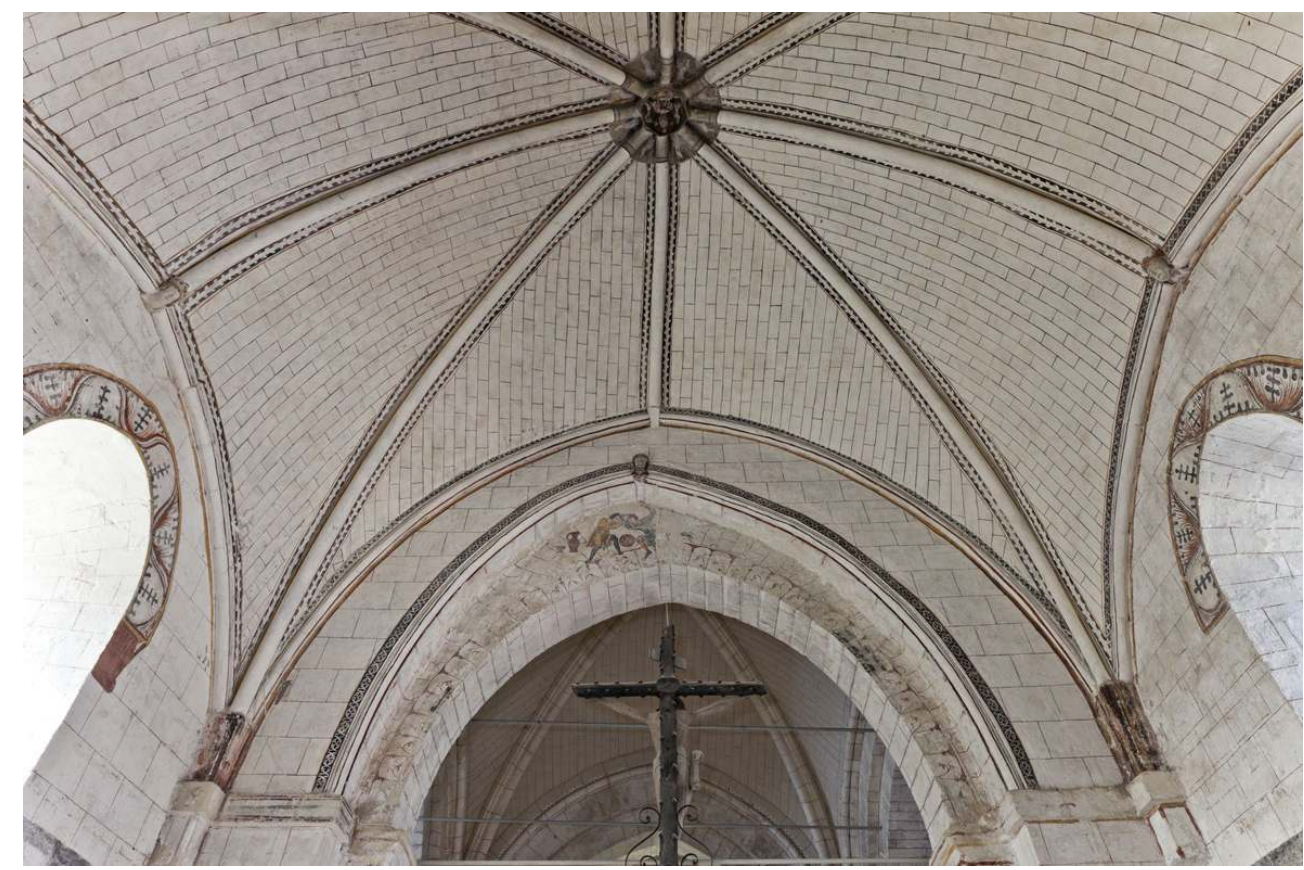

Pontigné (Maine-et-Loire), église paroissiale Saint-Denis, chœur, revers de l'arc de passage vers le chœur. Dispute entre joueurs de dés.

Phot. Guillotin, Yves. (C) Conseil régional des Pays de la Loire, service du patrimoine, 2012. IVR52_20124900992NUCA

Le renouvellement plus fréquent des édifices laïcs que celui des édifices cultuels fait que les peintures religieuses restent plus abondantes que les peintures profanes. Cependant, ces dernières deviennent de plus en plus nombreuses au fur et à mesure que les siècles médiévaux s'écoulent.

79 La reconsidération des acquis à la lumière de l'étude de la totalité des peintures murales médiévales constitue l'un des enjeux de cette étude, comme la fonction de support de communication privilégié tenue par la peinture murale au sein de la société médiévale par exemple.

\section{Des œuvres d'ordre exceptionnel ou emblématique}

80 L'analyse des résultats de la prospection montre qu'au moins un décor de peinture murale d'ordre exceptionnel ou emblématique est conservé dans chacun des cinq départements des Pays de la Loire. La connaissance scientifique acquise auparavant laissait supposer ce constat. Le caractère d'exception peut être dû à l'ampleur du décor ; à la qualité de l'artiste ou à celle du commanditaire ; à l'inventivité de l'œuvre ; à la technique employée ou à l'importance historique que l'œuvre a pu acquérir au cours du temps.

81 Le site de Vieux-Bourg à Saint-Sulpice-des-Landes en Loire-Atlantique conserve ainsi des peintures murales réalisées en plusieurs campagnes au $\mathrm{XV}^{\mathrm{e}}$ siècle. Peintures médiévales exceptionnellement conservées dans ce département, elles constituent un jalon important entre la production de la Loire et celle rencontrée en Bretagne. Les peintures murales de la cathédrale d'Angers, Maine-et-Loire, constituent l'un des sommets de la 
production picturale de l'Europe du milieu du XIII ${ }^{\mathrm{e}}$ siècle. Elles se situent à la pointe de la modernité et de l'innovation, tant technique qu'artistique. La restauration de la chapelle seigneuriale de Cossé-en-Champagne en Mayenne vient de s'achever (fig. n²7). Le programme iconographique est caractéristique de la piété seigneuriale au Moyen Âge. À côté d'images attendues, il présente des représentations originales qui témoignent du savoir des commanditaires. Le manoir de Bois-Doublet, à Saint-Célerin, et le château du Lude, tous deux en Sarthe, conservent deux ensembles civils du XVI ${ }^{\mathrm{e}}$ et du XVII ${ }^{\mathrm{e}}$ siècle de grand intérêt. L'un présente une chambre des batailles, l'autre un « studiolo » avec des scènes à l'antique. L'église Notre-Dame-du-Bon-Port aux Sables-d'Olonne en Vendée présente des peintures murales exécutées dans la seconde moitié du XIX ${ }^{\mathrm{e}}$ siècle et dans la première moitié $\mathrm{du} \mathrm{XX}^{\mathrm{e}}$ siècle. Ces différentes campagnes picturales forment un décor homogène et caractéristique d'une période étonnamment active dans ce domaine.

Figure 27

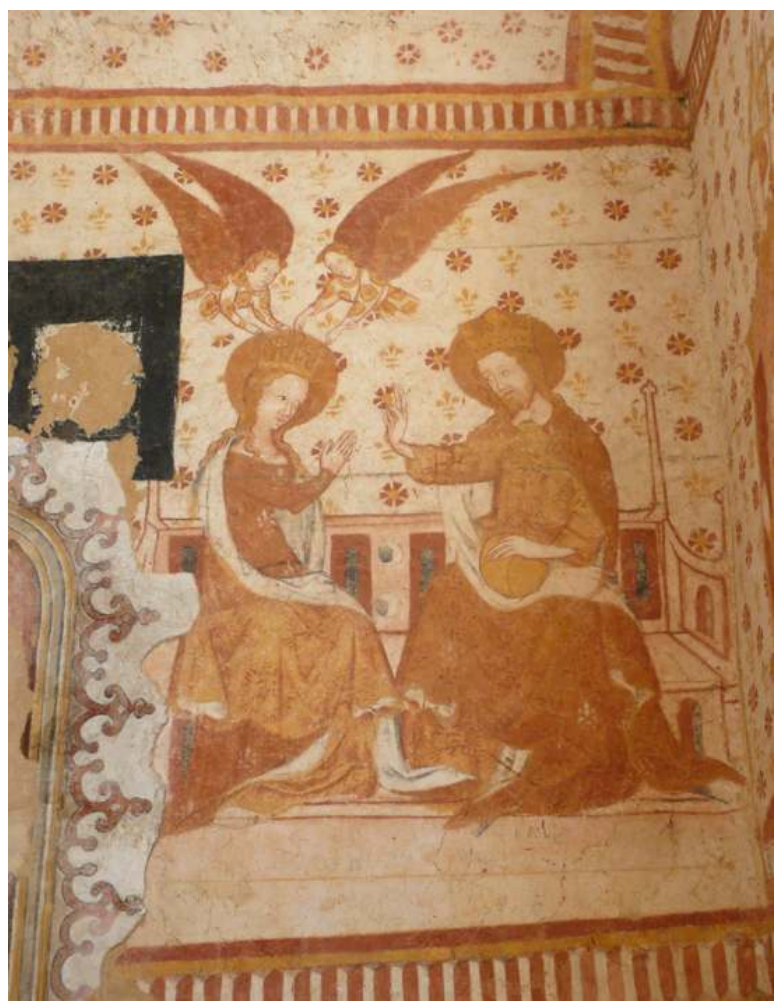

Cossé-en-Champagne (Mayenne), église paroissiale, chapelle méridionale. Le Couronnement de la Vierge.

Phot. Davy, Christian. (C) Christian Davy, 2012.

\section{NOTES}

1. - Cette contribution est issue du rapport administratif fourni par le service du patrimoine pour l'information des élus régionaux. Il a été distribué aux participants des premières rencontres 
régionales du patrimoine qui eurent lieu le 10 novembre 2011 à l'abbaye de Fontevraud. En 2012 il a été donné aux présidents des Conseils généraux des cinq départements et aux maires de toutes les communes de la région des Pays de la Loire.

2. - Cet inventaire est consultable sur le site : www.patrimoine.paysdelaloire.fr et un ouvrage a été publié. LEDUC-GUEYE, Christine. Décors peints. Pays de Haute-Sarthe et d'Alençon. Nantes : 303, 2012 (Parcours du Patrimoine, 377).

3. - Loire-Atlantique, Maine-et-Loire, Mayenne, Sarthe et Vendée.

\section{RÉSUMÉS}

La peinture murale a été retenue comme l'une des thématiques prioritaires par la Région des Pays de la Loire. Une opération de prospection a été menée en 2010 pour établir des axes de recherche approfondie. Les principaux résultats montrent que les Pays de la Loire sont une région riche en peintures murales réalisées du Moyen Âge aux années 2000 : quatre communes sur cinq possèdent au moins un édifice peint.

The wall painting was retained as one of the priority themes by the Region of Pays de la Loire. An operation of prospecting was led in 2010 to establish areas of detailed research. The main results show that Pays de la Loire are a region rich in wall painting realized between Middle Ages and 2000s: four municipalities on five possess at least a painted building.

\section{INDEX}

Mots-clés : peinture murale, fresque, décor peint, lambris peint, Moyen Âge, époque moderne, époque contemporaine, Pays de la Loire, Loire-Atlantique, Maine-et-Loire, Mayenne, Sarthe, Vendée, inventaire du patrimoine culturel, prospection, recensement, architecture religieuse, architecture civile, architecture publique, architecture industrielle, architecture domestique, iconographie religieuse, paysage, décor ornemental, décor figuré, décor historié

\section{AUTEUR}

\section{CHRISTIAN DAVY}

Chercheur au service du Patrimoine des Pays de la Loire Christian.DAVY@paysdelaloire.fr 